Gábor Vona

\title{
Providing new impetus to corporate well-being programmes: improving life expectancy through risk assessment
}

\author{
GÁBOR VONA \\ PhD Student \\ Corvinus University of Budapest \\ Institute of Business Economics \\ Department of Logistics and Supply Chain Management, \\ Hungary \\ Email: gabor.vona@uni-corvinus.hu
}

Diseases of the circulatory system are leading causes of death, which compel stakeholders to lessen cardiovascular risks by utilising more effective prevention. These risks can be estimated based on gender, age, smoker status, systolic blood pressure, and total cholesterol. Artificial neural networks enable modelling of 10-year cardiovascular mortality rates. Understandable communication of potential gains in life expectancy may enhance health consciousness through mitigating behavioural risks. The reproduction of death statistics requires the adjustment of the recommended probabilities for the occurrence of fatal cardiovascular events. This study deals with countries at high and low cardiovascular risk, selecting Hungary and the Czech Republic (high risk) and Austria (low risk). In Hungary, the gains in life expectancy are $(43.4-36.2=) 7.2^{1}$ years for females and $(37.4-28.0=) 9.4$ years for males, both aged 40 . These figures moderate to $(21.2-15.6=) 5.7^{2}$ and $(17.1-11.3=) 5.8$ years for elderly people aged 65 , respectively. The Czech Republic represents an interim phase between the two other countries regarding advancement in life expectancy, the respective gains exceed the Hungarian values: $(45.8-37.8=)$ 8.0, $(39.7-29.7=)$ 10.0 $(23.0-16.6=) 6.4$, and $(18.2-12.3=) 5.9$ years. In contrast, a 40-year-old woman may benefit from an additional $(46.6-41.3=) 5.3$ years in Austria, while the corresponding accrual for men is $(42.3-35.7=) 6.6$ years. On reaching 65 years, the increment is $(23.4-19.3=)$ 4.1 and $(20.0-16.1=) 3.9$ years.

KEYWORDS: life expectancy, well-being, cardiovascular risks

${ }^{1}$ The results are indicated as the difference in life expectancy between the best and worst observed health statuses.

${ }^{2}$ The indicated figures are correct; the difference in the decimal place is due to rounding.

Hungarian Statistical ReVIEW, Volume 4, NumBER 1, PP. 17-50. DOI: 10.35618/hsr2021.01.en017 
On $25^{\text {th }}$ September of 2015, the General Assembly of the United Nations adopted 17 Sustainable Development Goals (SDGs) to be achieved by 2030. The $3^{\text {rd }}$ SDG ('Ensure healthy lives and promote well-being for all at all ages') occupies a higher level in the hierarchy of goals as its accomplishment requires fulfilling and harmonising other SDGs. Figure 1 illustrates the relatively difficult advancement in the $3^{\text {rd }}$ SDG, which the present study aims at bolstering by virtue of its target of 'Strengthening the capacity of all countries, in particular developing countries, for early warning, risk reduction and management of national and global health risks' (United Nations [2020] pp. 1, 14, 17).

Figure 1. Causal dependencies between SDGs

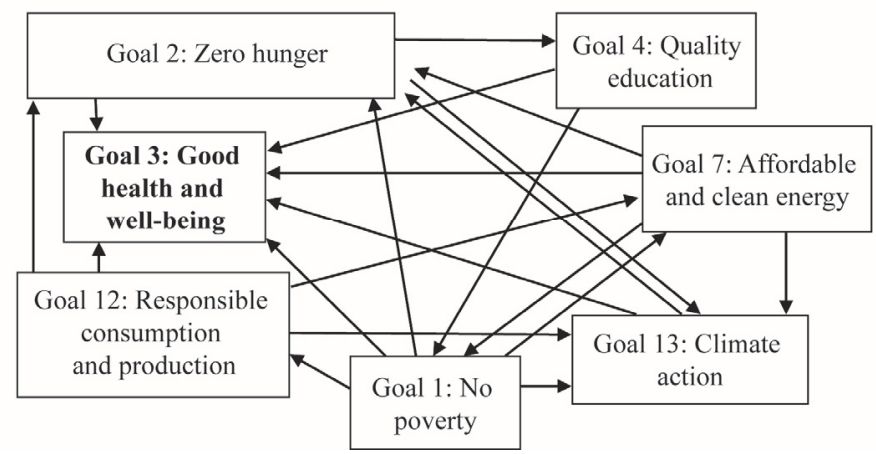

Note. Each arrow starts from the prerequisite.

Life expectancy (average number of years that a person can expect to live) and its subset, healthy life expectancy (the life expectancy reduced by the years lived in less than full health due to disease or injury) are indicators describing the current state of and the progress in well-being. Both can be calculated not only at birth but for all ages. Using the data of the countries of the EU (European Union) plus Norway and Iceland, the gender-independent estimate for the continually growing maximum of the healthy life expectancy valid for 2016 was 76.7 years at birth. In the same year, Spain represented the highest unisex healthy life expectancy at birth in Europe with 73.8 years. Only Japan (74.8 years) and Singapore (76.2 years) ranked before the Mediterranean state, whereas Hungary lagged behind with 66.8 years. An additional 8.7 years (for this data, see Vona [2020] pp. 99-100) could be achieved through

Hungarian Statistical ReVIEW, Volume 4, NuMBER 1, PP. 17-50. DOI: 10.35618/hsr2021.01.en017 
reduction in preventable causes of mortality via effective primary prevention and public health care. The remainder $(76.7-66.8-8.7=1.2$ years $)$ is lost owing to environmental factors. In the Czech Republic, healthy life expectancy is 69.3 years and the two respective components amount to 6.3 and 1.1 years. Austria, the third member of the triad demonstrates 72.4, 3.8, and 0.5 years (UNDP [2018] pp. 50, 53, Vona [2020] pp. 99-100). Another manifestation of the difference between the three countries can be captured in the life expectancy at birth: 72.9 years for Hungarian males and 79.3 years for females in 2019 compared to the estimated EU27 average in 2019 of 78.5 and 84.0 years, respectively. Both the Czech and Austrian figures exceed the Hungarian ones. At the same time, achieving the Japanese indicators (in 2019, 81.5 for men and 87.7 years for women) would make the retirement period extended for both sexes in Hungary by approximately one decade (HCSO [2021a], $E C$ [2021], UNDP [2020] p. 356). The practice of Spain affirms that generally effective public health and health care interventions are appropriate but not sufficient in terms of addressing premature mortality as mortality rates offer abundant leeway for improvement in spite of the advantage of Spaniards compared to the EU citizens. Furthermore, it projects the growing needs for health care and long-term care for elderly people in ageing societies $(O E C D-E O H S P$ [2019c] pp. 3, 22). This highlights the need to seek new opportunities and employ additional measures to boost both life expectancy and its subindicators.

As evident solutions can be considered building more on prevention and health promotion, involving relevant stakeholders and providing them with health risk assessment tools, which can establish an early warning system, could improve morbidity and preventable mortality plus alleviate overloaded health care systems. Regarding stakeholders, firms and non-governmental organisations can play a crucial role. In $2019,856,950$ active enterprises operated in Hungary (preliminary data) and the economically active population aged between 15 and 74 years exceeded 4.67 million persons (HCSO [2021b], HCSO e-Shelf [2021] Table 3.1.1). Running extended corporate well-being programmes may reduce the expenditures on sick-leave and sickpay (in 2019, they amounted to $[81+127=] 208$ billion HUF, which in total accounted for $0.44 \%$ of GDP; the number of calendar days of sick-leave and sick-pay was $[11.4+26.5=] 37.9$ million days (HCSO e-Shelf [2021] Tables 3.5.23, 3.5.24, 4.1.8). In addition, 2,791 health and 10,873 sport non-governmental organisations (the sum of the number of foundations and membership organisations) can be mobilised for spreading health consciousness (data valid for 2019; HCSO e-Shelf [2021] Table 4.2.14). In both the Czech Republic and Hungary, ischaemic heart disease, stroke, and cancer account for a significant share of deaths, while risk factors coupled with unhealthy behaviours (poor diet, smoking, alcohol consumption, and low physical activity) are responsible for half of all deaths (OECD-EOHSP [2019a] pp. $5,7,[2019$ b] pp. 5, 7). In contrast, this latter proportion is merely $39 \%$ in the EU.

Hungarian Statistical REVIEW, Volume 4, NuMBER 1, PP. 17-50. DOI: 10.35618/hsr2021.01.en017 
This study focuses on circulatory system diseases as they are the leading cause of death $(49.1 \%$ of all death cases in 2019 in Hungary and 42.2\% in the Czech Republic). Effective primary prevention performed by corporate well-being programmes may provide a remedy for this situation (HCSO [2020a] Table 6.2.20, Czech Statistical Office [2021a]).

This research is motivated by the idea that treating individuals as precious resources necessitates the recognition and spread of the value of prolonging health. Thus, the present study creates a basic risk assessment tool for cardiovascular risks that quantifies potential gains in life expectancy by shifting from a chosen initial health status towards more favourable targets. These risks are represented by a group of disorders including 'hypertension (high blood pressure), coronary heart disease (heart attack), cerebrovascular disease (stroke), peripheral vascular disease, heart failure, rheumatic heart disease, congenital heart disease, and cardiomyopathies' (WHO [2021]). The results confirm that the proposed tool can provide easily understandable increments in life expectancy. Hence, the chance that individuals are committed to health consciousness increases by generating multiple direct and indirect benefits, which reflects the practical relevance of the research in addition to its theoretical contribution.

\section{Literature review}

To identify a possible research gap, the extensive field of health promotion programmes is presented in a simplified way by aligning the most frequent streams of research, following a chronological order. Consequently, the review incorporating studies from the last two decades clarifies and outlines the main themes and development in the research field. On the one hand, the selected areas encompass definitions and conceptualisations of health and well-being, identifying the impacts of health promotion programmes on performance indicators such as work-related outcomes with special focus on financial results or customer loyalty, and quantifying these impacts (e.g. return of investment). On the other hand, cases analysing the relationship between health risk factors and an aggregate variable such as health-related costs or all-cause mortality, and refining the involved determinants when assessing risks to be managed within the framework of well-being programmes, have proved to be of interest. After a brief overview of the Hungarian literature, this listing is complemented with the role of company attributes (e.g. firm size) in the intensity of corporate well-being programmes, making use of new approaches supported by technology (e.g. gamification), and the concomitant benefits of increased well-being.

Hungarian STATISTICAL REVIEW, VOlume 4, NuMBER 1, PP. 17-50. DOI: 10.35618/hsr2021.01.en017 
Danna-Griffin's ([1999] pp. 357, 359-360) study can be considered as a basic work providing definitions and conceptualisations of health and well-being via a literature review. The authors' applied framework is based on three pillars represented by antecedents, well-being in the workplace, and consequences. Antecedents are divided into three categories: work settings, personality traits, and occupational stress. Well-being (both life and job-related satisfaction) is targeted at providing mental and physical health in the workplace. The third pillar unifies individual (physical, psychological, and behavioural) and organisational consequences (health insurance costs, productivity affected by absenteeism, etc.) to be relieved through improved wellbeing and health.

Aldana ([2001] pp. 296, 297, 299, 315, 317, 318) investigated the impact of health promotion programmes on financial outcomes with a primary focus on health care costs and employee productivity. Through an extended literature review of health intervention studies, the author revealed that stress, excessive body weight, and multiple risk factors are associated with increased health care costs and illnessrelated absenteeism. In contrast, lack of fitness (physical activity) implies only augmented health care costs but may not affect absence from work. Beyond mitigating many health risks, health promotion programmes result in lower levels of employee absenteeism and employee-related health care expenditures, while fitness programmes show only partial progress in the form of moderated health care costs.

Of the selected articles, two deal with workplace health promotion based on financial returns by applying the indicator of return on investment. Baicker-CutlerSong ([2010] pp. 304, 305, 308, 310) conducted a meta-analysis of the literature on costs and savings arising from employer-based wellness initiatives by putting decreased health care costs and lessened absenteeism at the forefront from the numerous potential benefits (e.g. improved health, ameliorating productivity, lower replacement costs for absent employees, firm's attractiveness when recruiting workers). They concluded that workplace disease prevention and wellness programmes can lead to savings (avoiding absenteeism costs and drop of medical costs) even in the short term; the underlying studies examined well-being programmes for 2-3 years on average. Baxter et al. ([2014] pp. 347, 357) examined the relationship between return on investment and quality of study methodology in workplace health promotion programmes by systematic literature search. Like Baiker-Cutler-Song [2010], they found a positive return on investment. Furthermore, they pointed to the phenomenon that studies of higher methodological quality demonstrated smaller financial returns.

Focusing on a frequently cited work (Goetzel et al. [1998]) ${ }^{3}$, Goetzel et al. ([2012] pp. 2475, 2478, 2480-2482) examined ten modifiable common health risk factors (depression, blood glucose, blood pressure, body weight, tobacco use, physical

${ }^{3}$ Alias the HERO [Health Enhancement Research Organisation] study.

Hungarian Statistical REVIEW, Volume 4, NuMBER 1, PP. 17-50. DOI: 10.35618/hsr2021.01.en017 
inactivity, stress, cholesterol, nutrition and eating habits, alcohol consumption) to support through cost prediction evidence-based health promotion and risk-reduction programmes. Despite variations in the prevalence of risks, the authors determined similar relationships between risks and medical expenditures after more than one decade. They identified seven of the listed health risks (exceptions: cholesterol, alcohol consumption, nutrition and eating habits) worth mitigating for reducing related future costs.

Loef-Walach ([2012] pp. 164, 165, 169) selected five lifestyle factors (smoking, diet, physical activity, alcohol consumption, obesity [high body mass index]) to evaluate the combined effects of at least three lifestyle factors and all-cause mortality. They revealed that, instead of focusing on single risk factors, addressing their combination can generate better results in abating the risk of disease at the individual level.

Grimani-Aboagye-Kwak ([2019] pp. 1, 3, 9, 10) conducted a systematic literature review and suggested that work-related outcomes (e.g. absenteeism, productivity, work performance, workability, and presenteeism ${ }^{4}$ ) can be positively influenced through workplace health promotion interventions targeted at nutritional behaviour and/or physical activity. These initiatives may affect combinations of individuals, the organisational structure, and the physical work environment.

Krekel-Ward-De Neve ([2019] pp. 2, 12, 17, 33-35, 38-40) studied the relationship between four performance outcomes and employee well-being by a meta-analysis to judge whether improving the latter dimension is coupled with enhanced productivity. Employee satisfaction demonstrated a significant positive correlation with customer loyalty, employee productivity, and profitability, while staff turnover showed a significant negative correlation. In addition, a broader term (employees' engagement) extending beyond satisfaction provided similar results with the four performance indicators by confirming the universal nature of the importance of employee well-being for corporate performance. Furthermore, the study highlighted distinct variations in the correlation both based on industries and geographical regions.

Numerous studies deal with cardiovascular diseases and their impacts on the quality of life by determining connections between them. Pinheiro et al. ([2019] pp. 1472-1473) concluded that self-reported health may be a complement to current approaches when identifying and treating cardiovascular risks.

Abandoning the selection of international articles, it is worth mentioning that the Budapest Management Review includes an investigation of the domain of improving employee well-being. Péter-Keller-Kaszás ([2013] p. 57) examined corporate activities focusing on the preservation of health and stated that micro and small enterprises internalise health consciousness into their organisational culture. Barna-Fodor ([2018] p. 8) investigated a gamified social solution and found that its

${ }^{4}$ Presenteeism refers to the lost productivity that occurs when employees are not fully performing their tasks owing to physical and/or mental problems like illness or other conditions.

Hungarian STATISTICAL REVIEW, Volume 4, NuMBER 1, PP. 17-50. DOI: 10.35618/hsr2021.01.en017 
use is apt for creating a better workplace atmosphere and integrating regular physical activity into the lifestyle of employees. Kovács-Martos ([2018] pp. 39-40) determined five distinct patterns with significantly different well-being indices based on a test measuring optimism as a reaction to situations.

Finally, Szabó-Juhász ([2019] pp. 157, 164, 166) examined workplace wellbeing programmes from the viewpoint of risk management. Stress, physical inactivity, presenteeism, overweight/obesity, and poor diet can be considered major workplace health risk factors in Europe. Physical inactivity, stress, obesity, unhealthy diet, smoking, high blood sugar, high blood pressure, depression, and alcohol consumption are the most important risk factors reducing productivity. Corporate well-being programmes can lessen fluctuation plus improve employee morale and work atmosphere. For example, they can create values through enhancing health consciousness among employees, or in the form of reducing absence from work and presenteeism coupled with increasing productivity.

Following my research objective of finding 'tangible' and easily interpretable metrics resulting in more health consciousness and raising life expectancy with particular reference to Hungary, the Czech Republic, and Austria, the application of risk assessment in the interest of diminishing cardiovascular risks emerged as a possible research gap. Consequently, this article establishes the basics of an effective risk assessment tool contributing to societal prosperity through strengthening the preventive components of corporate well-being programmes. Accordingly, the study aims at the following:

- estimating cardiovascular risks by age, gender, and further relevant parameters (Research question 1: How can cardiovascular risks be modelled?),

- quantifying the impact of cardiovascular risks on life expectancy based on various health statuses (Research questions 2-3: What are the life expectancies calculated based on the 10-year probabilities of fatal cardiovascular diseases as alternative metrics? What is the estimated maximum gender-and age-specific gain in life expectancy between the two extreme cases by minimising cardiovascular risks?).

\section{Methodology}

An artificial neural networks method (ANN) was designed in the statistical software IBM SPSS Statistics Version 25 to reproduce 10-year mortality rates due to

HuNGARIAN STATISTICAL REVIEW, VOLUME 4, NuMBER 1, PP. 17-50. DOI: 10.35618/hsr2021.01.en017 
fatal cardiovascular diseases. ANN is one of the machine learning methods that can be applied for regression. The multilayer perceptron (MLP) is a feedforward, supervised learning network that is a function of one or more predictors that minimises the prediction error of the dependent variable (IBM [2016] pp. 607-616).

The general architecture of MLP networks consists of the input layer, the hidden layer(s), and the output layer. SPSS restricts the number of possible hidden layers to two and offers the following activation functions:

a) Hyperbolic tangent: $f(x)=\tanh x=\frac{e^{x}-e^{-x}}{e^{x}+e^{-x}}$,

b) Sigmoid: $f(x)=\frac{1}{1+e^{-x}}$,

c) Identity: $f(x)=x$.

By introducing the denotations: $\mathbf{x}$ vector of the predictors, $p$ number of the independent variables, $q$ number of the neurons in the $1^{\text {st }}$ hidden layer, $r$ number of the neurons in the $2^{\text {nd }}$ hidden layer, $f$ activation function of the hidden layer(s), $g$ activation function of the output layer, $y$ output, $\mathbf{w}$ matrix or vector of the synaptic weights (parameter estimates), $b_{0}$ scalar, and $\mathbf{b}_{1}$ or $\mathbf{b}_{2}$ vector of the parameter estimates for the biases (intercepts) in the $1^{\text {st }}$ or $2^{\text {nd }}$ hidden layer, the dependent variable for one hidden layer can be determined as follows:

$$
y=g\left[\sum_{j=1}^{q} \mathbf{w}_{\mathbf{j}} \cdot f\left(\sum_{i=1}^{p} \mathbf{w}_{\mathbf{i j}} \cdot \mathbf{x}_{\mathbf{i}}+\mathbf{b}_{1 \mathbf{j}}\right)+b_{0}\right] .
$$

For two hidden layers, the additional layer renders the formula more complex:

$$
y=g\left\{\sum_{k=1}^{r} \mathbf{w}_{\mathbf{k}} \cdot f\left[\sum_{j=1}^{q} \mathbf{w}_{\mathbf{j} \mathbf{k}} \cdot f\left(\sum_{i=1}^{p} \mathbf{w}_{\mathbf{i j}} \cdot \mathbf{x}_{\mathbf{i}}+\mathbf{b}_{1 \mathbf{j}}\right)+\mathbf{b}_{2 \mathbf{k}}\right]+b_{0}\right\} .
$$

Modelling mortality is composed of two main steps: first, determining the mortality rates, and second, calculating the life expectancies as realisable gains (Office for National Statistics [2021]).

Gender-specific mortality rates are divided into a cardiovascular component $(\mathrm{CV})$ and a non-cardiovascular component (the remaining part unifying all other death causes; non $C V$ ). Mortality rates are denoted by $q_{x_{-} \text {total }}^{1}$, where $A$ in the upper 
index represents the whole population comprising all health statuses; for this reason, they arise from a population life table. $q_{x_{-}^{-}}^{1}{ }_{-t a l}^{-}$is the 1-year mortality rate, which is the probability that a person aged exactly $x$ will die due to any causes before his/her $(x+1)^{\text {th }}$ anniversary. $S$ refers to any single specific health status. By merging the two cases into one formula, we obtain

$$
q_{x_{-} \text {total }}^{1-k}=q_{x_{-} n o n C V}^{1}+q_{x_{-} C V}^{1{ }^{-} k}, \quad(k=\{A, S\}) .
$$

As the non-cardiovascular component will generally be applied irrespective of health status, the values are calculated in the order below:

$$
\begin{aligned}
& q_{x_{-} \text {non } C V}^{1}=q_{x_{-} \text {total }}^{1}-q_{x_{-} C V}^{1}, \\
& q_{x_{-} \text {total }}^{1}=q_{x_{-} \text {non } C V}^{1}+q_{x_{-}^{-} C V}^{1-S} .
\end{aligned}
$$

$q_{x_{-}-{ }_{C V}^{1}}^{k}$ is the 1-year mortality rate, which is the probability that a person aged exactly $x$ will die due to cardiovascular diseases before his/her $(x+1)^{\text {th }}$ anniversary. $q_{x_{-}{ }^{1}{ }^{k}}{ }^{k}$ is determined as follows:

$$
q_{x_{-} C V}^{10-k}=q_{x_{-}^{-} C V}^{1{ }^{k}}+\sum_{i=1}^{9}\left(\prod_{j=0}^{i-1} p_{x_{+j}^{-} A}^{1_{-} A}\right) \cdot q_{x_{+i_{-} C V}^{1} k}^{{ }^{k}},(k=\{A, S\}) .
$$

The $t$-year survival rate $p_{x}^{t_{-}{ }^{A}}$, perceived in the whole population, is the probability that a person aged exactly $x$ will reach the age $(x+t)$.

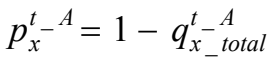

$$
\begin{aligned}
& p_{x}^{t-{ }^{A}}=\prod_{j=0}^{t-1} p_{x^{-}+j}^{1_{-}}
\end{aligned}
$$

To track the specificities of the underlying mortality table, the equality of the quotient of death probabilities due to any reasons and cardiovascular diseases is assumed as follows:

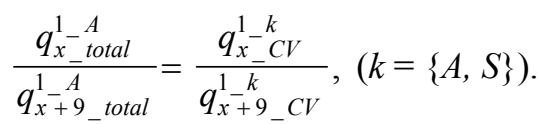


By assuming a geometric series for the sake of simplicity, the rates at various age at entry can be calculated

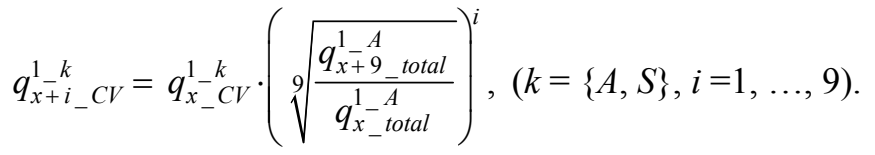

Cardiovascular mortality rates are generated based on the following equation derived from $/ 4 /$ and $/ 8 /$ :

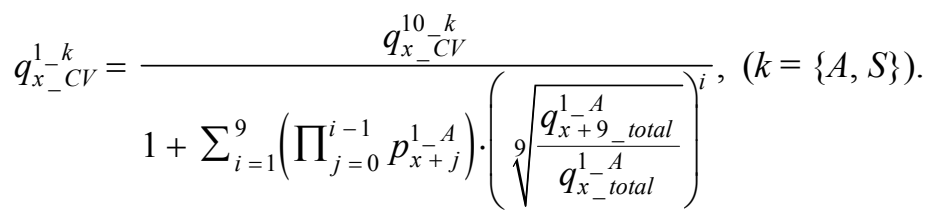

Owing to the lack of exact details, assumptions are introduced for estimating $q_{x_{-} C V}^{10-A}$. First, symmetric distributions regarding systolic blood pressure (120, 140, 160 , and $180 \mathrm{Hgmm})$ and total cholesterol $(4,5,6,7$, and $8 \mathrm{mmol} / \mathrm{l})$ are presumed (further details are provided under subsection 2.1.). Second, gender-specific smoking ratios are generally applied irrespective of age.

$e_{x}^{0-{ }^{k}}$ denotes the remaining life expectancy at the exact age $x$, which is the average number of years that those aged exactly $x$ will still live based on the $k$ mortality rates.

$$
e_{x}^{0-{ }^{k}}=\frac{\sum_{i=x}^{\omega} L_{i}^{k}}{l_{x}^{k}},(k=\{A, S\})
$$

$L_{x}^{k}$ is the total number of years alive of $l_{x}^{k}$ persons between the age $x$ and $x+1$ by assuming that death cases occur linearly over a year:

$$
L_{x}^{k}=\frac{l_{x}^{k}+l_{x+1}^{k}}{2},(k=\{A, S\}) .
$$

$l_{x}^{k}$ refers to the number of survivors aged exactly $x$ of 100,000 live births $\left(l_{0}=100,000\right)$ of the same sex who are assumed to be subject to the $k$ mortality rates $(k=\{A, S\})$ throughout their lives:

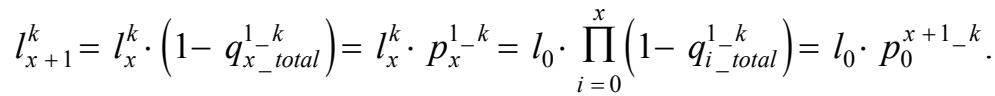


$q_{100}=1$ is assumed for each scenario $(A, S)$ regarding both genders. The impact of ignoring cases above 100 years on life expectancy is negligible. The potential gain is the difference in life expectancy pertaining to the initial $\left(S_{0}\right)$ and the more advantageous target health status $\left(S_{1}\right): e_{x}^{0-} S_{1}-e_{x}^{0}-^{S_{0}}$.

\subsection{Data collection}

The model assumptions incorporate five domains:

1. 10-year mortality rates of fatal cardiovascular diseases, generated by the functions provided by the MLP,

2. population mortality rates,

3. smoking ratios,

4. death statistics due to cardiovascular diseases,

5. population (i.e. the whole society) split by sex and age.

\section{0-year mortality rates of fatal cardiovascular disease}

Based on age-adjusted 2012 cardiovascular disease mortality rates, countries can be split into a group at high cardiovascular risk and that at low cardiovascular risk. For example, Hungary, the Czech Republic, and Poland fall in the former group while Austria, Germany, the United Kingdom, and Spain are low-risk countries given their more favourable rates (European Society of Cardiology [2016] pp. NP14-15). The analysis covers both country groups so that the impact of future progress in abating cardiovascular rates in Hungary can be estimated.

Discrete values of the risk estimation for the occurrence of fatal cardiovascular events within 10 years are shown in Tables 1 and 2. These so-called SCORE (Systematic Coronary Risk Estimation; European Society of Cardiology [2016] p. NP13) probabilities rely on five dimensions: gender (female [coded later with 2], male [1]), age $(40,50,55,60$, and 65 years), smoker status (only binary: nonsmoker [transformed later to 0], smoker [1]), systolic blood pressure (120, 140, 160, and $180 \mathrm{Hgmm})$, and total cholesterol $(4,5,6,7$, and $8 \mathrm{mmol} / \mathrm{l})$. Consequently, the total number of cases is $2 \times 5 \times 2 \times 4 \times 5=400$ for both tables.

HungaRian Statistical ReVIEW, Volume 4, NuMBER 1, PP. 17-50. DOI: 10.35618/hsr2021.01.en017 
Table 1

Probabilities for the occurrence of fatal cardiovascular events within 10 years countries at high cardiovascular risk (percentage)

\begin{tabular}{|c|c|c|c|c|c|c|c|c|c|c|c|}
\hline \multirow{3}{*}{ Age } & \multicolumn{5}{|c|}{ Non-smoker } & \multicolumn{5}{|c|}{ Smoker } & \multirow{3}{*}{$\begin{array}{l}\text { Systolic } \\
\text { blood } \\
\text { pressure } \\
(\text { Hgmm })\end{array}$} \\
\hline & 4 & 5 & 6 & 7 & 8 & 4 & 5 & 6 & 7 & 8 & \\
\hline & \multicolumn{10}{|c|}{ total cholesterol $(\mathrm{mmol} / \mathrm{l})$} & \\
\hline & \multicolumn{11}{|c|}{ Females } \\
\hline 65 & 7 & 8 & 9 & 10 & 12 & 13 & 15 & 17 & 19 & 22 & 180 \\
\hline 65 & 5 & 5 & 6 & 7 & 8 & 9 & 10 & 12 & 13 & 16 & 160 \\
\hline 65 & 3 & 3 & 4 & 5 & 6 & 6 & 7 & 8 & 9 & 11 & 140 \\
\hline 65 & 2 & 2 & 3 & 3 & 4 & 4 & 5 & 5 & 6 & 7 & 120 \\
\hline 60 & 4 & 4 & 5 & 6 & 7 & 8 & 9 & 10 & 11 & 13 & 180 \\
\hline 60 & 3 & 3 & 3 & 4 & 5 & 5 & 6 & 7 & 8 & 9 & 160 \\
\hline 60 & 2 & 2 & 2 & 3 & 3 & 3 & 4 & 5 & 5 & 6 & 140 \\
\hline 60 & 1 & 1 & 2 & 2 & 2 & 2 & 3 & 3 & 4 & 4 & 120 \\
\hline 55 & 2 & 2 & 3 & 3 & 4 & 4 & 5 & 5 & 6 & 7 & 180 \\
\hline 55 & 1 & 2 & 2 & 2 & 3 & 3 & 3 & 4 & 4 & 5 & 160 \\
\hline 55 & 1 & 1 & 1 & 1 & 2 & 2 & 2 & 2 & 3 & 3 & 140 \\
\hline 55 & 1 & 1 & 1 & 1 & 1 & 1 & 1 & 2 & 2 & 2 & 120 \\
\hline 50 & 1 & 1 & 1 & 2 & 2 & 2 & 2 & 3 & 3 & 4 & 180 \\
\hline 50 & 1 & 1 & 1 & 1 & 1 & 1 & 2 & 2 & 2 & 3 & 160 \\
\hline 50 & 0 & 1 & 1 & 1 & 1 & 1 & 1 & 1 & 1 & 2 & 140 \\
\hline 50 & 0 & 0 & 1 & 1 & 1 & 1 & 1 & 1 & 1 & 1 & 120 \\
\hline 40 & 0 & 0 & 0 & 0 & 0 & 0 & 0 & 0 & 1 & 1 & 180 \\
\hline 40 & 0 & 0 & 0 & 0 & 0 & 0 & 0 & 0 & 0 & 0 & 160 \\
\hline 40 & 0 & 0 & 0 & 0 & 0 & 0 & 0 & 0 & 0 & 0 & 140 \\
\hline \multirow[t]{2}{*}{40} & 0 & 0 & 0 & 0 & 0 & 0 & 0 & 0 & 0 & 0 & 120 \\
\hline & \multicolumn{11}{|c|}{ Males } \\
\hline 65 & 14 & 16 & 19 & 22 & 26 & 26 & 30 & 35 & 41 & 47 & 180 \\
\hline 65 & 9 & 11 & 13 & 15 & 16 & 18 & 21 & 25 & 29 & 34 & 160 \\
\hline 65 & 6 & 8 & 9 & 11 & 13 & 13 & 15 & 17 & 20 & 24 & 140 \\
\hline 65 & 4 & 5 & 6 & 7 & 9 & 9 & 10 & 12 & 14 & 17 & 120 \\
\hline 60 & 9 & 11 & 13 & 15 & 18 & 18 & 21 & 24 & 28 & 33 & 180 \\
\hline 60 & 6 & 7 & 9 & 10 & 12 & 12 & 14 & 17 & 20 & 24 & 160 \\
\hline 60 & 4 & 5 & 6 & 7 & 9 & 8 & 10 & 12 & 14 & 17 & 140 \\
\hline 60 & 3 & 3 & 4 & 5 & 6 & 6 & 7 & 8 & 10 & 12 & 120 \\
\hline 55 & 6 & 7 & 8 & 10 & 12 & 12 & 13 & 16 & 19 & 22 & 180 \\
\hline 55 & 4 & 5 & 6 & 7 & 8 & 8 & 9 & 11 & 13 & 16 & 160 \\
\hline 55 & 3 & 3 & 4 & 5 & 6 & 5 & 6 & 8 & 9 & 11 & 140 \\
\hline 55 & 2 & 2 & 3 & 3 & 4 & 4 & 4 & 5 & 6 & 8 & 120 \\
\hline 50 & 4 & 4 & 5 & 6 & 7 & 7 & 8 & 10 & 12 & 14 & 180 \\
\hline 50 & 2 & 3 & 3 & 4 & 5 & 5 & 6 & 7 & 8 & 10 & 160 \\
\hline 50 & 2 & 2 & 2 & 3 & 3 & 3 & 4 & 5 & 6 & 7 & 140 \\
\hline 50 & 1 & 1 & 2 & 2 & 2 & 2 & 3 & 3 & 4 & 5 & 120 \\
\hline 40 & 1 & 1 & 1 & 2 & 2 & 2 & 2 & 3 & 3 & 4 & 180 \\
\hline 40 & 1 & 1 & 1 & 1 & 1 & 1 & 2 & 2 & 2 & 3 & 160 \\
\hline 40 & 0 & 1 & 1 & 1 & 1 & 1 & 1 & 1 & 2 & 2 & 140 \\
\hline 40 & 0 & 0 & 1 & 1 & 1 & 1 & 1 & 1 & 1 & 1 & 120 \\
\hline
\end{tabular}

Source: European Society of Cardiology ([2016] p. NP13). 
Table 2

Probabilities for the occurrence of fatal cardiovascular events within 10 years countries at low cardiovascular risk (percentage)

\begin{tabular}{|c|c|c|c|c|c|c|c|c|c|c|c|}
\hline \multirow{3}{*}{ Age } & \multicolumn{5}{|c|}{ Non-smoker } & \multicolumn{5}{|c|}{ Smoker } & \multirow{3}{*}{$\begin{array}{l}\text { Systolic } \\
\text { blood } \\
\text { pressure } \\
\text { (Hgmm) }\end{array}$} \\
\hline & 4 & 5 & 6 & 7 & 8 & 4 & 5 & 6 & 7 & 8 & \\
\hline & \multicolumn{10}{|c|}{ total cholesterol $(\mathrm{mmol} / \mathrm{l})$} & \\
\hline & \multicolumn{11}{|c|}{ Females } \\
\hline 65 & 4 & 5 & 6 & 6 & 7 & 9 & 9 & 11 & 12 & 14 & 180 \\
\hline 65 & 3 & 3 & 4 & 4 & 5 & 6 & 6 & 7 & 8 & 10 & 160 \\
\hline 65 & 2 & 2 & 2 & 3 & 3 & 4 & 4 & 5 & 6 & 7 & 140 \\
\hline 65 & 1 & 1 & 2 & 2 & 2 & 3 & 3 & 3 & 4 & 4 & 120 \\
\hline 60 & 3 & 3 & 3 & 4 & 4 & 5 & 5 & 6 & 7 & 8 & 180 \\
\hline 60 & 2 & 2 & 2 & 2 & 3 & 3 & 4 & 4 & 5 & 5 & 160 \\
\hline 60 & 1 & 1 & 1 & 2 & 2 & 2 & 2 & 3 & 3 & 4 & 140 \\
\hline 60 & 1 & 1 & 1 & 1 & 1 & 1 & 2 & 2 & 2 & 3 & 120 \\
\hline 55 & 1 & 1 & 2 & 2 & 2 & 3 & 3 & 3 & 4 & 4 & 180 \\
\hline 55 & 1 & 1 & 1 & 1 & 1 & 2 & 2 & 2 & 3 & 3 & 160 \\
\hline 55 & 1 & 1 & 1 & 1 & 1 & 1 & 1 & 1 & 2 & 2 & 140 \\
\hline 55 & 0 & 0 & 1 & 1 & 1 & 1 & 1 & 1 & 1 & 1 & 120 \\
\hline 50 & 1 & 1 & 1 & 1 & 1 & 1 & 1 & 2 & 2 & 2 & 180 \\
\hline 50 & 0 & 0 & 1 & 1 & 1 & 1 & 1 & 1 & 1 & 1 & 160 \\
\hline 50 & 0 & 0 & 0 & 0 & 0 & 1 & 1 & 1 & 1 & 1 & 140 \\
\hline 50 & 0 & 0 & 0 & 0 & 0 & 0 & 0 & 0 & 1 & 1 & 120 \\
\hline 40 & 0 & 0 & 0 & 0 & 0 & 0 & 0 & 0 & 0 & 0 & 180 \\
\hline 40 & 0 & 0 & 0 & 0 & 0 & 0 & 0 & 0 & 0 & 0 & 160 \\
\hline 40 & 0 & 0 & 0 & 0 & 0 & 0 & 0 & 0 & 0 & 0 & 140 \\
\hline \multirow[t]{2}{*}{40} & 0 & 0 & 0 & 0 & 0 & 0 & 0 & 0 & 0 & 0 & 120 \\
\hline & \multicolumn{11}{|c|}{ Males } \\
\hline 65 & 8 & 9 & 10 & 12 & 14 & 15 & 17 & 20 & 23 & 26 & 180 \\
\hline 65 & 5 & 6 & 7 & 8 & 10 & 10 & 12 & 14 & 16 & 19 & 160 \\
\hline 65 & 4 & 4 & 5 & 6 & 7 & 7 & 8 & 9 & 11 & 13 & 140 \\
\hline 65 & 2 & 3 & 3 & 4 & 5 & 5 & 5 & 6 & 8 & 9 & 120 \\
\hline 60 & 5 & 6 & 7 & 8 & 9 & 10 & 11 & 13 & 15 & 18 & 180 \\
\hline 60 & 3 & 4 & 5 & 5 & 6 & 7 & 8 & 9 & 11 & 13 & 160 \\
\hline 60 & 2 & 3 & 3 & 4 & 4 & 5 & 5 & 6 & 7 & 9 & 140 \\
\hline 60 & 2 & 2 & 2 & 3 & 3 & 3 & 4 & 4 & 5 & 6 & 120 \\
\hline 55 & 3 & 4 & 4 & 5 & 6 & 6 & 7 & 8 & 10 & 12 & 180 \\
\hline 55 & 2 & 2 & 3 & 3 & 4 & 4 & 5 & 6 & 7 & 8 & 160 \\
\hline 55 & 1 & 2 & 2 & 2 & 3 & 3 & 3 & 4 & 5 & 6 & 140 \\
\hline 55 & 1 & 1 & 1 & 2 & 2 & 2 & 2 & 3 & 3 & 4 & 120 \\
\hline 50 & 2 & 2 & 3 & 3 & 4 & 4 & 4 & 5 & 6 & 7 & 180 \\
\hline 50 & 1 & 1 & 2 & 2 & 2 & 2 & 3 & 3 & 4 & 5 & 160 \\
\hline 50 & 1 & 1 & 1 & 1 & 2 & 2 & 2 & 2 & 3 & 3 & 140 \\
\hline 50 & 1 & 1 & 1 & 1 & 1 & 1 & 1 & 2 & 2 & 2 & 120 \\
\hline 40 & 0 & 1 & 1 & 1 & 1 & 1 & 1 & 1 & 2 & 2 & 180 \\
\hline 40 & 0 & 0 & 0 & 1 & 1 & 1 & 1 & 1 & 1 & 1 & 160 \\
\hline 40 & 0 & 0 & 0 & 0 & 0 & 0 & 1 & 1 & 1 & 1 & 140 \\
\hline 40 & 0 & 0 & 0 & 0 & 0 & 0 & 0 & 0 & 1 & 1 & 120 \\
\hline
\end{tabular}

Source: European Society of Cardiology ([2016] p. NP14). 


\section{Population mortality rates}

Gender-specific mortality rates were collected from suitable mortality tables. The life expectancy at birth and the underlying mortality tables for the selected countries are summarised in Table 3 .

Table 3

Life expectancy at birth in Hungary, the Czech Republic, and Austria

\begin{tabular}{l|c|c}
\hline \multicolumn{1}{c|}{ Country } & Males & Females \\
\hline Hungary & 72.9 years $(2019)$ & 79.3 years $(2019)$ \\
\hline Czech Republic & 76.3 years $(2019)$ & 82.1 years $(2019)$ \\
\hline Austria & 79.5 years $(2019)$ & 84.2 years $(2019)$ \\
\hline
\end{tabular}

Note. The years of mortality tables are in parentheses.

Source: HCSO ([2020a] Tables 6.2.15. and 6.2.16), Czech Statistical Office [2021b], Statistik Austria [2021a].

\section{Smoking ratios}

Table 4 displays the gender-specific smoking ratios applied irrespective of age. The last available data are from 2014 or 2017.

Table 4

Share of smokers (percentage of population aged 15 years and over)

\begin{tabular}{l|c|c}
\hline \multicolumn{1}{c|}{ Country } & Males & Females \\
\hline Hungary (2014) & 31.6 & 20.8 \\
\hline Czech Republic (2017) & 22.6 & 14.5 \\
\hline Austria (2014) & 26.5 & 22.1 \\
\hline
\end{tabular}

Note. The years of data are in parentheses.

Source: OECD iLibrary ([2021] Figure 4.1)

\section{Death statistics due to cardiovascular diseases}

In this case, the selected year is 2019 for each country. According to the international classification of ICD-10 (International Statistical Classification of Diseases and Related Health Problems, $10^{\text {th }}$ Revision), diseases of the circulatory system are assigned to the codes I00-I99 (WHO [2019]). Although the practices of statistical 
offices in disclosing number of deceased persons are dissimilar in details, the codes I00-I99 cover the following items:

- I00-I02 Acute rheumatic fever

- I05-I09 Chronic rheumatic heart diseases

- I10-I15 Hypertensive diseases

- I20-I25 Ischaemic heart diseases

- I26-I28 Pulmonary heart disease and diseases of pulmonary circulation

- I30-I52 Other forms of heart disease

- I60-I69 Cerebrovascular diseases

- I70-I79 Diseases of arteries, arterioles, and capillaries

- I80-I89 Diseases of veins, lymphatic vessels, and lymph nodes, not elsewhere classified

- I95-I99 Other and unspecified disorders of the circulatory system.

\section{Population split by sex and age}

As the above-mentioned 10-year mortality rates due to fatal cardiovascular diseases do not consider country-specific phenomena, Hungarian demographic statistics (one of the countries at high cardiovascular risk; HCSO [2020a] Tables 6.2.18 and $6.2 .19,[2020 \mathrm{~b}])$ split by age group have served as a basis for comparison to partially validate the modelled number of deaths due to cardiovascular diseases. The product corresponding to the number of the Hungarian population and the estimated 1-year mortality rate due to fatal cardiovascular diseases was contrasted with the actual number of deaths at the aggregated level of age groups. The same estimations were conducted in the cases of the Czech Republic (Czech Statistical Office [2021a], [2021c]) and Austria (Statistik Austria [2021b], [2021c]). The set of assumptions (population mortality rates of 2019, death statistics due to cardiovascular diseases in 2019, and population split by sex and age) is consistent regarding Hungary and the Czech Republic as the initial population refers to the $31^{\text {st }}$ December of 2018 (CZ) or

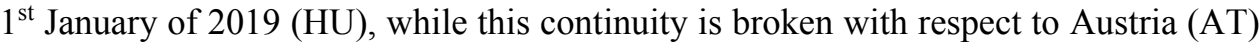
because of the population data valid for the $31^{\text {st }}$ October of 2018 .

\subsection{Data analysis}

Even if the assumptions may be subject to limitations, they are comprehensive and ensure the calculations provide valuable findings. First, an adequate model for generating 10-year mortality rates due to fatal cardiovascular diseases was

Hungarian Statistical ReVIEW, Volume 4, NumBER 1, PP. 17-50. DOI: 10.35618/hsr2021.01.en017 
established through MLP for both country groups. Subsequently, mortality rates differentiated by health status were determined so that life expectancies could be calculated. After validating the results with fact statistics, adjustments were performed to address the prevailing country-specific phenomena.

\section{Findings}

Research question 1: How can cardiovascular risks be modelled?

The current model limited to selected discrete values was extended to a general prediction of the 10-year probability of fatal cardiovascular diseases by assuming four different model types for both country groups. Prior to the runs, age, systolic blood pressure, total cholesterol, and cardiovascular probabilities were standardised. The results shown below are based on them. Table 5 presents the outcomes of the runs by applying the whole sample (400-400 records, here simultaneously identical with the population) as a training dataset. The sum of squared errors is calculated as the sum of the squares of the differences between the original non-standardised SCORE probabilities (see Tables 1 and 2) and the non-standardised MLP predicted values, both are expressed in percentages. The correlation is calculated from the same non-standardised values. The analysis begins with the countries at high cardiovascular risk and continues with the group at low risk following the same logic.

Table 5

Results of the models

\begin{tabular}{c|c|c|c|c|c|c|c}
\hline \multirow{2}{*}{ Model type } & \multirow{2}{*}{$\begin{array}{c}\text { Number of } \\
\text { hidden layers }\end{array}$} & \multicolumn{2}{|c|}{ Activation function } & \multicolumn{2}{c|}{ Correlation (\%) } & \multicolumn{2}{c}{ Sum of squared errors } \\
\cline { 4 - 8 } & & Hidden layer & Output layer & High risk & Low risk & High risk & Low risk \\
\hline & 1 & $\tanh$ & Identity & 99.83 & 99.66 & 64.48 & 41.03 \\
\hline 2 & 2 & $\tanh$ & Identity & 99.81 & 99.71 & 73.97 & 35.11 \\
\hline 3 & 1 & Sigmoid & Identity & 99.81 & 99.65 & 73.44 & 42.35 \\
\hline 4 & 2 & Sigmoid & Identity & 99.73 & 99.66 & 102.86 & 40.87 \\
\hline
\end{tabular}

In Table 5, Model type 1 produces the best goodness of fit for countries at high cardiovascular risk: one hidden layer composed of four neurons with hyperbolic tangent activation function for the hidden layer and with identity activation function for the output layer. Contrary to the previous case, Model type 2 is the most appropriate in the case of low cardiovascular risk: two hidden layers, the first consisting of

Hungarian Statistical REVIEW, Volume 4, NuMBER 1, PP. 17-50. DOI: 10.35618/hsr2021.01.en017 
four neurons, the second of three neurons, with hyperbolic tangent activation function for the hidden layers and with identity activation function for the output layer.

Figure 2 depicts the structure of the neurons, while Table 6 summarises the parameter estimates for countries at high cardiovascular risk.

Figure 2. Synaptic weights - countries at high cardiovascular risk

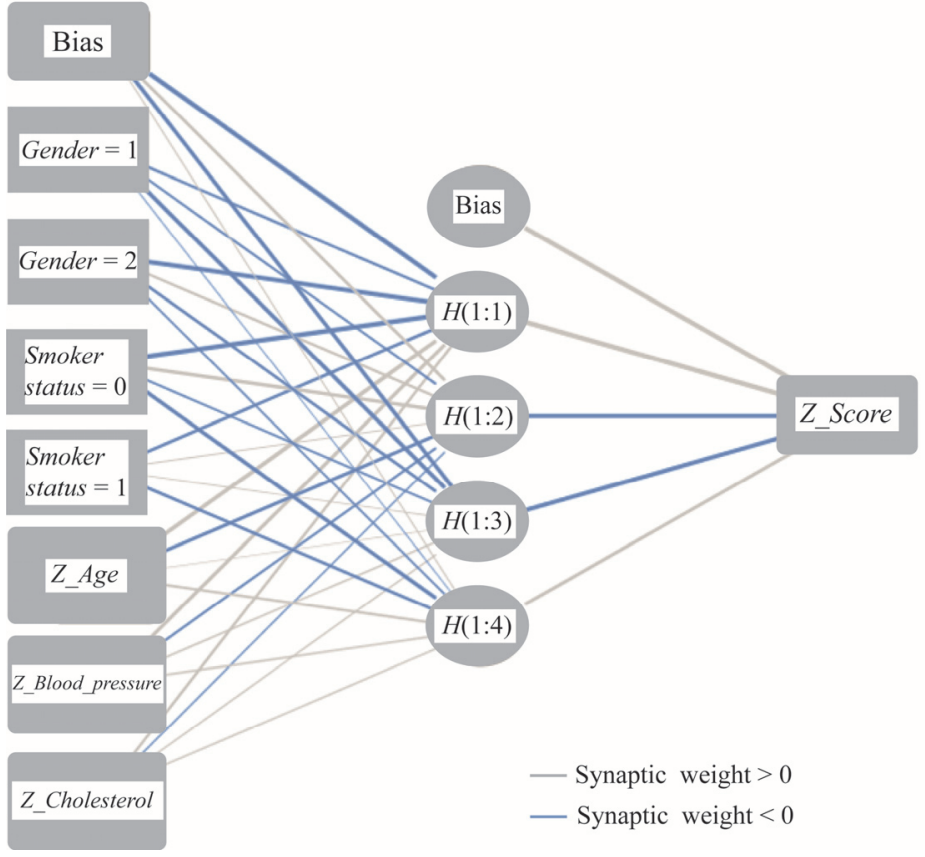

Table 6

Synaptic weights - countries at high cardiovascular risk

\begin{tabular}{|c|c|c|c|c|c|c|}
\hline & \multirow{3}{*}{ Predictor } & \multicolumn{5}{|c|}{ Predicted } \\
\hline & & \multicolumn{4}{|c|}{ Hidden layer } & \multirow{2}{*}{$\frac{\text { Output layer }}{\text { Z_Score }}$} \\
\hline & & $H(1: 1)$ & $H(1: 2)$ & $H(1: 3)$ & $H(1: 4)$ & \\
\hline \multirow[t]{8}{*}{ Input layer } & (Bias) & -1.457 & 0.639 & -0.762 & 0.151 & \\
\hline & {$[$ Gender $=1]$} & -0.351 & -0.334 & -0.777 & -0.022 & \\
\hline & {$[$ Gender $=2]$} & -1.425 & 0.387 & -0.497 & -0.272 & \\
\hline & {$[$ Smoker_status $=0]$} & -1.578 & 0.662 & -0.277 & -0.730 & \\
\hline & {$[$ Smoker_status $=1]$} & -0.502 & 0.036 & 0.023 & -0.498 & \\
\hline & Z_Age & 1.032 & -0.643 & 0.021 & 0.349 & \\
\hline & Z_Blood_pressure & 0.690 & -0.345 & 0.238 & 0.248 & \\
\hline & Z_Cholesterol & 0.391 & -0.168 & 0.216 & 0.217 & \\
\hline
\end{tabular}

Hungarian StatisticAl ReVIEW, Volume 4, NuMBER 1, PP. 17-50. DOI: 10.35618/hsr2021.01.en017 


\begin{tabular}{|c|c|c|c|c|c|c|}
\hline & \multirow{3}{*}{ Predictor } & \multicolumn{5}{|c|}{ Predicted } \\
\hline & & \multicolumn{4}{|c|}{ Hidden layer } & Output layer \\
\hline & & $H(1: 1)$ & $H(1: 2)$ & $H(1: 3)$ & $H(1: 4)$ & Z_Score \\
\hline \multirow[t]{5}{*}{ Hidden layer } & (Bias) & & & & & 2.201 \\
\hline & $H(1: 1)$ & & & & & 2.470 \\
\hline & $H(1: 2)$ & & & & & -1.223 \\
\hline & $H(1: 3)$ & & & & & -1.321 \\
\hline & $H(1: 4)$ & & & & & 0.659 \\
\hline
\end{tabular}

For countries at low cardiovascular risk, the structure of the neurons is illustrated in Figure 3 and the parameter estimates are reported in Table 7.

Figure 3. Synaptic weights - countries at low cardiovascular risk

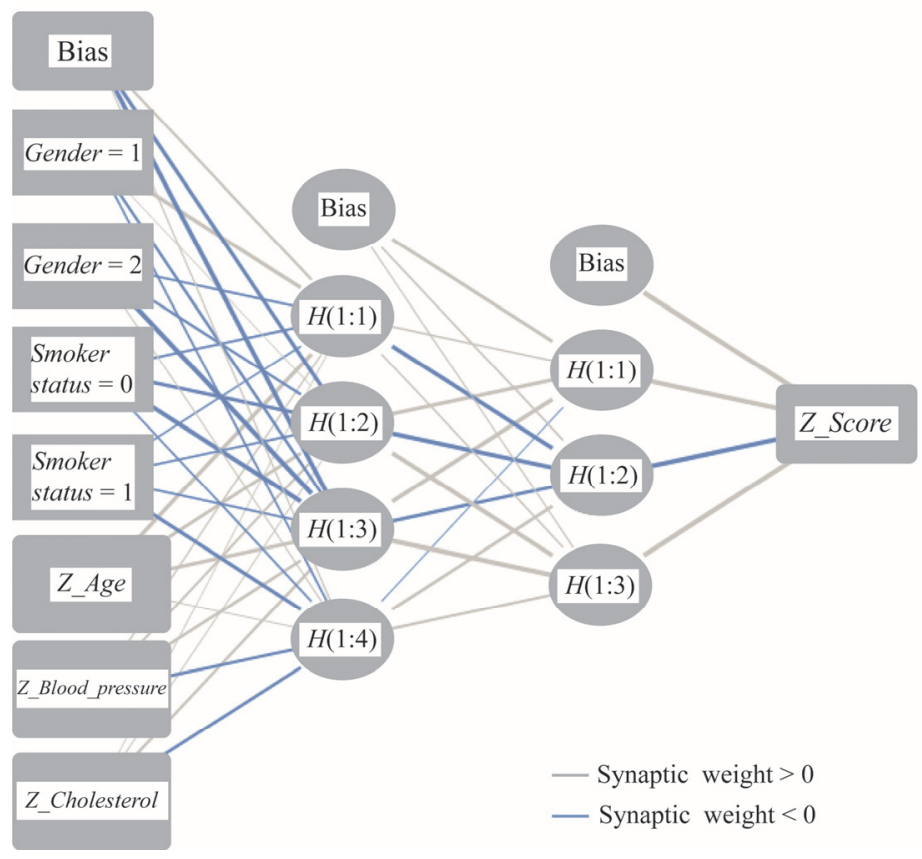

HungaRian Statistical ReVIEW, VOluME 4, NuMBER 1, PP. 17-50. DOI: 10.35618/hsr2021.01.en017 
Synaptic weights - countries at low cardiovascular risk

\begin{tabular}{|c|c|c|c|c|c|}
\hline \multirow{3}{*}{\multicolumn{2}{|c|}{ Predictor }} & \multicolumn{4}{|c|}{ Predicted } \\
\hline & & \multicolumn{4}{|c|}{ Hidden layer 1} \\
\hline & & $H(1: 1)$ & $H(1: 2)$ & $H(1: 3)$ & $H(1: 4)$ \\
\hline \multirow[t]{8}{*}{ Input layer } & (Bias) & 0.260 & -0.592 & -0.992 & 0.056 \\
\hline & {$[$ Gender $=1]$} & 0.641 & 0.003 & -0.301 & -0.119 \\
\hline & {$[$ Gender $=2]$} & -0.213 & -0.242 & -1.076 & 0.035 \\
\hline & {$[$ Smoker_status $=0]$} & -0.236 & -0.537 & -0.837 & -0.106 \\
\hline & {$[$ Smoker_status $=1]$} & -0.089 & -0.163 & -0.162 & -0.548 \\
\hline & Z_Age & 0.654 & 0.516 & 0.589 & 0.024 \\
\hline & Z_Blood_pressure & 0.067 & 0.232 & 0.398 & -0.382 \\
\hline & Z_Cholesterol & 0.007 & 0.020 & 0.322 & -0.452 \\
\hline
\end{tabular}

\begin{tabular}{|c|c|c|c|c|c|}
\hline & & \multicolumn{4}{|c|}{ Predicted } \\
\hline \multirow{2}{*}{\multicolumn{2}{|c|}{ Predictor }} & \multicolumn{3}{|c|}{ Hidden layer 2} & \multirow{2}{*}{$\frac{\text { Output layer }}{\text { Z_Score }}$} \\
\hline & & $H(2: 1)$ & $H(2: 2)$ & $H(2: 3)$ & \\
\hline \multirow[t]{5}{*}{ Hidden layer 1} & (Bias) & 0.534 & 0.110 & 0,055 & \\
\hline & $H(1: 1)$ & 0.102 & -0.671 & 0,070 & \\
\hline & $H(1: 2)$ & 0.605 & -0.742 & 0,814 & \\
\hline & $H(1: 3)$ & 0.688 & -0.530 & 1,481 & \\
\hline & $H(1: 4)$ & -0.011 & 0.472 & 0,281 & \\
\hline \multirow[t]{4}{*}{ Hidden layer 2} & (Bias) & & & & 2.954 \\
\hline & $H(2: 1)$ & & & & 1.440 \\
\hline & $H(2: 2)$ & & & & -1.054 \\
\hline & $H(2: 3)$ & & & & 1.882 \\
\hline
\end{tabular}

According to Table 8 , age is the most influencing factor on the 10 -year probability of fatal cardiovascular diseases and gender ranks $3^{\text {rd }}$ for both cases. Although fixed circumstances have a more deterministic role than factors on which individuals may exercise effects, considerable improvements can be achieved through mitigating cardiovascular risks by means of more health consciousness. Interestingly, by fixing age, all other determinants proved to be less highly ranked in low-risk countries compared to the high-risk states, presumably due to more developed health systems. 


\begin{tabular}{l|c|c|c|c}
\multicolumn{4}{c}{$\begin{array}{c}\text { Importance of the independent variables - comparison between } \\
\text { countries at high and low cardiovascular risk }\end{array}$} \\
\hline \multirow{2}{*}{ Independent variable } & $\begin{array}{c}\text { Importance of the independent } \\
\text { variables }\end{array}$ & Normalized importance (\%) \\
\cline { 2 - 5 } & High risk & Low risk & High risk & Low risk \\
\hline \multirow{2}{*}{ Gender } & 0.168 & 0.148 & 44.2 & 36.8 \\
\hline Smoker_status & 0.120 & 0.125 & 31.7 & 31.0 \\
\hline Z_Age & 0.380 & 0.402 & 100.0 & 100.0 \\
\hline Z_Blood_pressure & 0.207 & 0.211 & 54.4 & 52.6 \\
\hline Z_Cholesterol & 0.125 & 0.115 & 32.9 & 28.5 \\
\hline
\end{tabular}

Research questions 2-3: What are the life expectancies calculated based on the 10-year probabilities of fatal cardiovascular diseases as alternative metrics? What is the estimated maximum gender-and age-specific gain in life expectancy between the two extreme cases by minimising cardiovascular risks?

The life expectancy of the best (non-smoker, $120 \mathrm{Hgmm}$ systolic blood pressure, $4 \mathrm{mmol} / 1$ total cholesterol; denoted by index $B$ ) and the worst health status (smoker, $180 \mathrm{Hgmm}$ systolic blood pressure, $8 \mathrm{mmol} / \mathrm{l}$ total cholesterol; identified by index $W$ ) was modelled between the age of 40 and 65 . The maximum potential gain is the difference between the life expectancy calculated with the best mortality rates

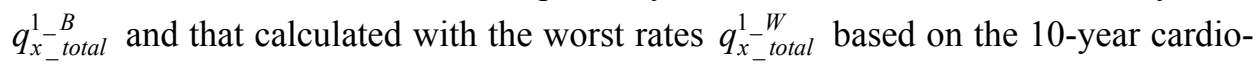
vascular mortality rates $q_{x_{-} C V}^{10-B}$ and $q_{x_{-} C V}^{10-W}$.

Table 9

Potential gains in life expectancy through minimising cardiovascular risks based on Hungarian mortality rates and smoking ratios (years)

\begin{tabular}{l|l|l|l|l|l|l|l|l}
\hline \multirow{2}{*}{ Age } & \multicolumn{4}{|c|}{ Females } & \multicolumn{4}{c}{ Males } \\
\cline { 2 - 10 } & Basic & Best & Worst & Gain & Basic & Best & Worst & Gain \\
\hline \multirow{2}{*}{40} & 40.1 & 42.6 & 35.8 & 6.8 & 34.1 & 38.1 & 28.4 & 9.8 \\
\hline 45 & 35.4 & 37.8 & 30.9 & 6.9 & 29.5 & 33.4 & 23.9 & 9.5 \\
\hline 50 & 30.7 & 33.1 & 26.3 & 6.8 & 25.1 & 28.9 & 19.9 & 9.0 \\
\hline 55 & 26.2 & 28.6 & 22.1 & 6.5 & 21.1 & 24.7 & 16.3 & 8.4 \\
\hline 60 & 22.0 & 24.3 & 18.3 & 6.0 & 17.6 & 20.9 & 13.5 & 7.4 \\
\hline 65 & 18.1 & 20.2 & 14.9 & 5.3 & 14.5 & 17.5 & 11.5 & 6.0 \\
\hline
\end{tabular}

Note. Basic (whole population $)=e_{x}^{0-^{A}}$, best $=e_{x}^{0-^{B}}$, worst $=e_{x}^{0-^{W}}$, gain $=e_{x}^{0{ }^{-}{ }^{B}-e_{x}^{0}-^{W}}$. 
For testing the validity of the 1-year cardiovascular mortality rates for the whole population, aggregated Hungarian demographic statistics are available at the level of age groups. Table 10 splits the aggregate of 63,609 death cases into subcategories by indicating the underlying diseases of the circulatory system.

Table 10

Number of deceased persons due to diseases of the circulatory system in Hungary, 2019

\begin{tabular}{|c|c|c|c|c|}
\hline Cause of death & Males & Females & Total & Share $(\%)$ \\
\hline Hypertensive diseases & 3,525 & 6,284 & 9,809 & 15.4 \\
\hline - Essential (primary) hypertension & 774 & 1,644 & 2,418 & 3.8 \\
\hline - Hypertensive heart disease & 2,149 & 3,444 & 5,593 & 8.8 \\
\hline - Hypertensive renal disease & 244 & 484 & 728 & 1.1 \\
\hline - Hypertensive heart and renal disease & 358 & 712 & 1,070 & 1.7 \\
\hline Ischaemic heart diseases & 14,587 & 17,083 & 31,670 & 49.8 \\
\hline - Acute myocardial infarction & 3,301 & 2,398 & 5,699 & 9.0 \\
\hline - Chronic ischaemic heart disease & 11,197 & 14,582 & 25,779 & 40.5 \\
\hline - Other ischaemic heart disease & 89 & 103 & 192 & 0.3 \\
\hline Other forms of heart disease & 3,391 & 3,479 & 6,870 & 10.8 \\
\hline Cerebrovascular diseases & 4,981 & 6,507 & 11,488 & 18.1 \\
\hline - Intracerebral haemorrhage & 879 & 769 & 1,648 & 2.6 \\
\hline $\begin{array}{l}\text { - Cerebral infarction; occlusion and stenosis of } \\
\text { cerebral arteries, not resulting in cerebral } \\
\text { infarction }\end{array}$ & 2,103 & 2,657 & 4,760 & 7.5 \\
\hline - Other cerebrovascular disease & 1,999 & 3,081 & 5,080 & 8.0 \\
\hline Atherosclerosis & 956 & 1,421 & 2,377 & 3.7 \\
\hline Other disorders of the circulatory system & 704 & 691 & 1,395 & 2.2 \\
\hline Total & 28,144 & 35,465 & 63,609 & 100.0 \\
\hline Population, 1 January 2019 & $4,675,821$ & $5,096,935$ & $9,772,756$ & - \\
\hline
\end{tabular}

Source: HCSO ([2020a] Tables 6.2.18, 6.2.19, and 6.2.20), HCSO e-Shelf([2021] Table 2.1), WHO [2019].

The number of deaths split by age group was determined. Table 11 contrasts the real data with the estimated number of deceased persons as the product of the mortality rates $q_{x_{-}^{-}{ }_{C}^{-} C}^{-A}$ relying on Hungarian life tables and the number of Hungarian population aged $x$. As the ratios between fact and estimate substantially deviate from $100 \%$, these ratios were applied as multipliers to amend the assumption of symmetric distribution in such a way that the modelled results can be reconciled with the fact data. The results after adjustment are presented in Table 12 . 
Table 11

Actual deaths due to cardiovascular diseases in Hungary in 2019 and respective estimated values based on Hungarian mortality rates and smoking ratios

\begin{tabular}{c|c|c|c|r|c|c}
\hline \multirow{2}{*}{ Age } & \multicolumn{2}{|c|}{ Actual CVD deaths } & \multicolumn{2}{c|}{ Estimated CVD deaths } & \multicolumn{2}{c}{ Actual/estimated CVD deaths (\%) } \\
\cline { 2 - 7 } & Males & Females & Males & Females & Males & Females \\
\hline \multirow{2}{*}{$40-44$} & 288 & 74 & 380 & 46 & 76 & 161 \\
\hline $45-49$ & 520 & 154 & 605 & 135 & 86 & 114 \\
\hline $50-54$ & 901 & 254 & 1,015 & 295 & 89 & 86 \\
\hline $55-59$ & 1,433 & 489 & 1,677 & 606 & 85 & 81 \\
\hline $60-64$ & 2,731 & 1,118 & 3,429 & 1,378 & 80 & 81 \\
\hline $65-69$ & 3,614 & 1,850 & 4,294 & 1,929 & 84 & 96 \\
\hline $70-74$ & 3,708 & 2,664 & 4,463 & 2,321 & 83 & 115 \\
\hline $75-79$ & 4,266 & 4,721 & 4,335 & 3,016 & 98 & 157 \\
\hline $80-84$ & 4,145 & 7,318 & 3,362 & 3,623 & 123 & 202 \\
\hline $85-89$ & 3,874 & 8,753 & 3,076 & 4,703 & 126 & 186 \\
\hline $90-$ & 2,473 & 8,003 & 5,701 & 14,604 & 43 & 55 \\
\hline Total & 27,953 & 35,398 & 32,337 & 32,654 & 86 & 108 \\
\hline
\end{tabular}

Note. CVD deaths: deaths due to cardiovascular diseases. The estimated CVD deaths are rounded values, which explains the alteration in their indicated sum of 32,654 from the expected value of 32,656 after addition.

Table 12

Potential gains in life expectancy through minimising cardiovascular risks based on Hungarian mortality rates and smoking ratios, after adjustment with the multipliers (years)

\begin{tabular}{l|c|c|c|c|c|c|c|c}
\hline \multirow{2}{*}{ Age } & \multicolumn{5}{|c|}{ Females } & \multicolumn{4}{c}{ Males } \\
\cline { 2 - 9 } & Basic & Best & Worst & Gain & Basic & Best & Worst & Gain \\
\hline 40 & 40.1 & 43.4 & 36.2 & 7.2 & 34.1 & 37.4 & 28.0 & 9.4 \\
\hline 45 & 35.4 & 38.6 & 31.4 & 7.2 & 29.5 & 32.7 & 23.6 & 9.1 \\
\hline 50 & 30.7 & 33.9 & 26.8 & 7.1 & 25.1 & 28.2 & 19.6 & 8.7 \\
\hline 55 & 26.2 & 29.5 & 22.6 & 6.9 & 21.1 & 24.1 & 16.1 & 8.0 \\
\hline 60 & 22.0 & 25.2 & 18.8 & 6.4 & 17.6 & 20.4 & 13.3 & 7.1 \\
\hline 65 & 18.1 & 21.2 & 15.6 & 5.7 & 14.5 & 17.1 & 11.3 & 5.8 \\
\hline
\end{tabular}

Following the same procedure, the investigation continues with the Czech Republic. 
Potential gains in life expectancy through minimising cardiovascular risks based on Czech mortality rates and smoking ratios (years)

\begin{tabular}{l|c|c|c|c|c|c|c|c}
\hline \multirow{2}{*}{ Age } & \multicolumn{4}{|c|}{ Females } & \multicolumn{4}{c}{ Males } \\
\cline { 2 - 10 } & Basic & Best & Worst & Gain & Basic & Best & Worst & Gain \\
\hline 40 & 42.8 & 45.3 & 37.8 & 7.4 & 37.6 & 41.8 & 30.8 & 11.0 \\
\hline 45 & 38.0 & 40.5 & 33.0 & 7.5 & 32.9 & 37.0 & 26.5 & 10.6 \\
\hline 50 & 33.3 & 35.7 & 28.4 & 7.4 & 28.4 & 32.3 & 22.4 & 9.9 \\
\hline 55 & 28.6 & 31.0 & 24.0 & 7.0 & 24.0 & 27.8 & 18.8 & 9.1 \\
\hline 60 & 24.2 & 26.4 & 20.0 & 6.5 & 20.0 & 23.4 & 15.5 & 7.9 \\
\hline 65 & 19.9 & 22.0 & 16.3 & 5.7 & 16.3 & 19.3 & 12.9 & 6.4 \\
\hline
\end{tabular}

Table 14 divides the aggregate of 47,393 death cases due to diseases of the circulatory system into subcategories. The more favourable prevalence of these illnesses in the Czech Republic is remarkable.

Table 14

Number of deceased persons due to diseases of the circulatory system in the Czech Republic, 2019 (extract)

\begin{tabular}{l|r|r|r|r}
\hline \multicolumn{1}{c|}{ Cause of death } & Males & Females & Total & Share (\%) \\
\hline Hypertensive diseases & 1,487 & 2,436 & 3,923 & 8.3 \\
\hline Ischaemic heart diseases & 11,197 & 11,139 & 22,336 & 47.1 \\
\hline - Acute myocardial infarction & 2,259 & 1,534 & 3,793 & 8.0 \\
\hline - Chronic ischaemic heart disease & 8,621 & 9,428 & 18,049 & 38.1 \\
\hline - Other ischaemic heart disease & 317 & 177 & 494 & 1.0 \\
\hline Other forms of heart disease & 4,541 & 5,120 & 9,661 & 20.4 \\
\hline Cerebrovascular diseases & 3,218 & 4,201 & 7,419 & 15.7 \\
\hline Atherosclerosis & 684 & 851 & 1,535 & 3.2 \\
\hline Other disorders of the circulatory system & 1,201 & 1,318 & 2,519 & 5.3 \\
\hline Total & 22,328 & 25,065 & 47,393 & 100.0 \\
\hline Population, 31 December 2018 & $5,244,194$ & $5,405,606$ & $10,649,800$ & - \\
\hline
\end{tabular}

Source: Czech Statistical Office [2021a], [2021c]; WHO [2019].

Table 15 contrasts the real data with the estimated number of deceased persons to determine the multipliers for adjustment. Table 16 contains the results after adjustment. 
Table 15

Actual deaths due to cardiovascular diseases in the Czech Republic in 2019 and respective estimated values based on Czech mortality rates and smoking ratios

\begin{tabular}{c|r|r|r|r|r|r}
\hline \multirow{2}{*}{ Age } & \multicolumn{2}{|c|}{ Actual CVD deaths } & \multicolumn{2}{c|}{ Estimated CVD deaths } & \multicolumn{2}{c}{$\begin{array}{c}\text { Actual/estimated CVD } \\
\text { deaths (\%) }\end{array}$} \\
\cline { 2 - 7 } & Males & Females & Males & Females & Males & Females \\
\hline \multirow{2}{*}{$40-44$} & 154 & 55 & 455 & 56 & 34 & 97 \\
\hline $45-49$ & 309 & 103 & 707 & 155 & 44 & 66 \\
\hline $50-54$ & 497 & 138 & 1,053 & 300 & 47 & 46 \\
\hline $55-59$ & 802 & 268 & 1,505 & 527 & 53 & 51 \\
\hline $60-64$ & 1,508 & 552 & 2,771 & 1,056 & 54 & 52 \\
\hline $65-69$ & 2,485 & 983 & 4,212 & 1,733 & 59 & 57 \\
\hline $70-74$ & 3,417 & 1,976 & 5,067 & 2,405 & 67 & 82 \\
\hline $75-79$ & 3,444 & 2,949 & 4,464 & 2,632 & 77 & 112 \\
\hline $80-84$ & 3,421 & 4,239 & 3,789 & 3,056 & 90 & 139 \\
\hline $85-89$ & 3,604 & 6,431 & 3,418 & 4,025 & 105 & 160 \\
\hline $90-94$ & 2,006 & 5,288 & 1,641 & 3,115 & 122 & 170 \\
\hline $95-$ & 517 & 1,988 & 667 & 2,089 & 78 & 95 \\
\hline Total & 22,164 & 24,970 & 29,748 & 21,149 & 75 & 118 \\
\hline & & & & & & \\
\hline
\end{tabular}

Note. CVD deaths: deaths due to cardiovascular diseases. The estimated CVD deaths are rounded values, which explains the alteration in their indicated sum of 29,748 from the expected value of 29,749 after addition.

Table 16

Potential gains in life expectancy through minimising cardiovascular risks based on Czech mortality rates and smoking ratios, after adjustment with the multipliers (years)

\begin{tabular}{l|c|c|c|c|c|c|c|c}
\hline \multirow{2}{*}{ Age } & \multicolumn{4}{|c}{ Females } & \multicolumn{5}{c}{ Males } \\
\cline { 2 - 11 } & Basic & Best & Worst & Gain & Basic & Best & Worst & Gain \\
\hline \multirow{2}{*}{40} & 42.8 & 45.8 & 37.8 & 8.0 & 37.6 & 39.7 & 29.7 & 10.0 \\
\hline 45 & 38.0 & 41.0 & 33.0 & 8.1 & 32.9 & 35.0 & 25.4 & 9.6 \\
\hline 50 & 33.3 & 36.3 & 28.3 & 8.0 & 28.4 & 30.5 & 21.4 & 9.1 \\
\hline 55 & 28.6 & 31.7 & 24.0 & 7.7 & 24.0 & 26.1 & 17.9 & 8.3 \\
\hline 60 & 24.2 & 27.2 & 20.1 & 7.1 & 20.0 & 22.0 & 14.7 & 7.3 \\
\hline 65 & 19.9 & 23.0 & 16.6 & 6.4 & 16.3 & 18.2 & 12.3 & 5.9 \\
\hline
\end{tabular}

Finally, as one of the countries at low cardiovascular risk, Austria is examined. The relationship between the corresponding values of Tables 9, 13, and 17 shows 
a more favourable situation in the Czech Republic than in Hungary, while Austria surpasses both not only regarding the life expectancy at birth (see Table 3) but also later in life.

Potential gains in life expectancy through minimising cardiovascular risks based on Austrian mortality rates and smoking ratios (years)

\begin{tabular}{l|c|c|c|c|c|c|c|c}
\hline \multirow{2}{*}{ Age } & \multicolumn{4}{|c|}{ Females } & \multicolumn{4}{c}{ Males } \\
\cline { 2 - 10 } & Basic & Best & Worst & Gain & Basic & Best & Worst & Gain \\
\hline 40 & 44.9 & 46.8 & 41.4 & 5.4 & 40.7 & 43.2 & 36.3 & 6.9 \\
\hline 45 & 40.0 & 41.9 & 36.6 & 5.3 & 35.9 & 38.4 & 31.7 & 6.7 \\
\hline 50 & 35.2 & 37.1 & 31.9 & 5.2 & 31.3 & 33.7 & 27.4 & 6.3 \\
\hline 55 & 30.6 & 32.4 & 27.4 & 4.9 & 26.8 & 29.0 & 23.2 & 5.8 \\
\hline 60 & 26.0 & 27.7 & 23.2 & 4.6 & 22.5 & 24.6 & 19.5 & 5.1 \\
\hline 65 & 21.6 & 23.2 & 19.2 & 4.1 & 18.5 & 20.3 & 16.3 & 4.0 \\
\hline
\end{tabular}

Similar to the case of Hungary, these preliminary results without adjustment should be treated with reservations. The previous procedure was repeated, and Tables 18-20 highlight the results for Austria. Based on the share of ischaemic heart diseases and cerebrovascular diseases, the order of countries (Austria has the lowest proportion, thus $\mathrm{AT}<\mathrm{CZ}<\mathrm{HU}$ ) is inverse to that determined in the case of life expectancy $(\mathrm{HU}<\mathrm{CZ}<\mathrm{AT})$.

Table 18

Number of deceased persons due to diseases of the circulatory system in Austria, 2019 (extract)

\begin{tabular}{|c|c|c|c|c|}
\hline Cause of death & Males & Females & Total & Share \\
\hline Ischaemic heart diseases & 7,076 & 6,260 & 13,336 & 41.48 \\
\hline - Acute myocardial infarction & 2,582 & 1,744 & 4,326 & 13.46 \\
\hline $\begin{array}{l}\text { - Other ischaemic heart disease (including } \\
\text { chronic ischaemic heart disease) }\end{array}$ & 4,494 & 4,516 & 9,010 & 28.03 \\
\hline Other forms of heart disease & 2,635 & 3,914 & 6,549 & 20.37 \\
\hline Cerebrovascular diseases & 1,969 & 2,764 & 4,733 & 14.72 \\
\hline Total & 14,335 & 17,813 & 32,148 & 100.00 \\
\hline Population, 31 October 2018 & $4,351,670$ & $4,499,747$ & $8,851,417$ & - \\
\hline
\end{tabular}

Note. The source does not allow a more detailed presentation of death cases. Thus, the total sum deviates from the sum of the indicated categories.

Source: Statistik Austria [2021b], [2021c]. 
Actual deaths due to cardiovascular diseases in Austria in 2019 and respective estimated values based on Austrian mortality rates and smoking ratios

\begin{tabular}{c|c|c|c|c|c|c}
\hline \multirow{2}{*}{ Age } & \multicolumn{2}{|c|}{ Actual CVD deaths } & \multicolumn{2}{c}{ Estimated CVD deaths } & \multicolumn{2}{c}{$\begin{array}{c}\text { Actual/estimated CVD } \\
\text { deaths (\%) }\end{array}$} \\
\cline { 2 - 7 } & Males & Females & Males & Females & Males & Females \\
\hline \multirow{2}{*}{$40-44$} & 51 & 24 & 128 & 9 & 40 & 259 \\
\hline $45-49$ & 151 & 44 & 298 & 61 & 51 & 73 \\
\hline $50-54$ & 266 & 99 & 549 & 166 & 48 & 60 \\
\hline $55-59$ & 450 & 153 & 871 & 328 & 52 & 47 \\
\hline $60-64$ & 678 & 214 & 1,128 & 522 & 60 & 41 \\
\hline $65-69$ & 866 & 414 & 1,503 & 807 & 58 & 51 \\
\hline $70-74$ & 1,303 & 758 & 1,851 & 1,081 & 70 & 70 \\
\hline $75-79$ & 2,218 & 1,562 & 2,410 & 1,460 & 92 & 107 \\
\hline $80-84$ & 2,450 & 2,473 & 1,848 & 1,404 & 133 & 176 \\
\hline $85-89$ & 2,986 & 4,452 & 1,903 & 2,101 & 157 & 212 \\
\hline $90-94$ & 2,136 & 4,884 & 2,883 & 6,640 & 74 & 74 \\
\hline $95-$ & 697 & 2,706 & 988 & 3,609 & 71 & 75 \\
\hline Total & 14,252 & 17,783 & 16,360 & 18,188 & 87 & 98 \\
\hline
\end{tabular}

Note. CVD deaths: deaths due to cardiovascular diseases.

Table 20

Potential gains in life expectancy through minimising cardiovascular risks based on Austrian mortality rates and smoking ratios, after adjustment with the multipliers (years)

\begin{tabular}{l|c|c|c|c|c|c|c|c}
\hline \multirow{2}{*}{ Age } & \multicolumn{4}{|c|}{ Females } & \multicolumn{4}{c}{ Males } \\
\cline { 2 - 11 } & Basic & Best & Worst & Gain & Basic & Best & Worst & Gain \\
\hline 40 & 44.9 & 46.6 & 41.3 & 5.3 & 40.7 & 42.3 & 35.7 & 6.6 \\
\hline 45 & 40.0 & 41.8 & 36.5 & 5.2 & 35.9 & 37.6 & 31.1 & 6.4 \\
\hline 50 & 35.2 & 37.0 & 31.9 & 5.1 & 31.3 & 32.9 & 26.8 & 6.1 \\
\hline 55 & 30.6 & 32.3 & 27.4 & 4.9 & 26.8 & 28.4 & 22.8 & 5.6 \\
\hline 60 & 26.0 & 27.7 & 23.2 & 4.6 & 22.5 & 24.1 & 19.2 & 4.9 \\
\hline 65 & 21.6 & 23.4 & 19.3 & 4.1 & 18.5 & 20.0 & 16.1 & 3.9 \\
\hline
\end{tabular}

The free-to-download tables (A1-A3) of the online Annex to this study (see http://www.ksh.hu/statszemle_archive/en/2021/2021_01/2021_01_017_annex.xlsx) align the life expectancies for each health status by applying a positive approach 
compared to the practice of relying on the mortality rates due to cardiovascular diseases. Each table enables individuals to select a starting and a target health status for a given combination of gender, age, smoker status, systolic blood pressure, and total cholesterol. Instead of operating with death probabilities, communicating the life expectancies and the realisable accrual in life expectancy can be more motivating for eliminating behavioural risks. The results confirm that the statement regarding the order of countries ( $\mathrm{HU}<\mathrm{CZ}<\mathrm{AT}$ ) based on the life expectancy can be generalised to each health status.

\section{Discussion}

Opting for ANN was an appropriate choice for reproducing the 10-year cardiovascular mortality rates and filling in the missing values between 40 and 65 years and beyond. The worst 10 -year cardiovascular mortality rates above 65 years are reported in Table 21 and demonstrate a reasonable fit to Tables 1 and 2 for both risk types.

Table 21

Probabilities for the occurrence of fatal cardiovascular events within 10 years - estimations from 70 years (percentage)

\begin{tabular}{l|c|c|c|c}
\hline \multirow{2}{*}{ Age } & \multicolumn{2}{|c|}{ High risk } & \multicolumn{2}{c}{ Low risk } \\
\cline { 2 - 5 } & Females & Males & Females & Males \\
\hline \multirow{2}{*}{} & \multicolumn{4}{|c}{ Estimation } \\
\hline 95 & 55 & 57 & 31 & 31 \\
\hline 90 & 55 & 57 & 31 & 31 \\
\hline 85 & 54 & 57 & 31 & 31 \\
\hline 80 & 51 & 56 & 30 & 31 \\
\hline 75 & 45 & 55 & 27 & 30 \\
\hline 70 & 35 & 52 & 21 & 29 \\
\hline & & \multicolumn{5}{|c}{ Actual } \\
\hline 65 & 22 & 47 & 14 & 26 \\
\hline
\end{tabular}

After adjusting the cardiovascular mortality rates, plausible life expectancies could be calculated for each combination of gender, age, smoker status, systolic blood pressure, and total cholesterol, which can serve as tailored arguments for stim-

Hungarian Statistical REVIEW, Volume 4, NuMBER 1, PP. 17-50. DOI: 10.35618/hsr2021.01.en017 
ulating commitments towards a healthier lifestyle. By focusing on the two extreme cases regarding the investigated health statuses, Hungarian women aged 40 years can count on an additional 7.2 years. For men at the same age, the figure is 9.4 years. Ageing entails the shrinking of these indicators. At the age of 65, the increment amounting to 5.7 years for women and to 5.8 years for men is still considerable and convincing for a change in habits. The inhabitants of the Czech Republic can benefit from 8.0, 10.0, 6.4, and 5.9 years, respectively. Compared to the two members of the Visegrád Four, Austria qualifies as one of the countries at low cardiovascular risk, which manifested in lower values. The forecast is 5.3 years for 40 -year-old females and 6.6 years for males. On reaching 65 years, the augmentation in life expectancy wanes to 4.1 and 3.9 years, respectively.

Figures 4 and 5 illustrate the life expectancies for the best health status and the gains in life expectancies between the best and worst health statuses. Figure 5 highlights the fact that the better cardiovascular rates do not counterbalance the gender gap in the three countries, hence, Hungarian females may benefit from longer life expectancy than Austrian males.

Figure 4. Country comparison: life expectancies for the best health status split by gender

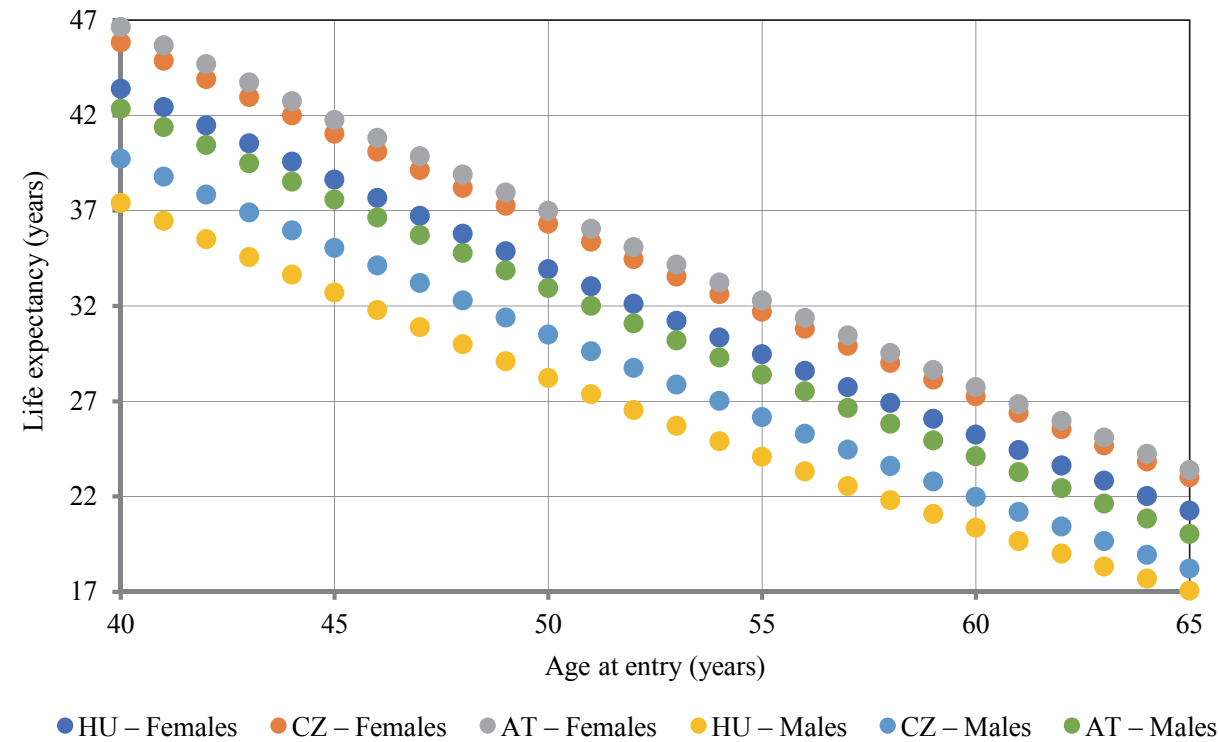

Figure 5 emphasises that Czech males can realise the highest gains up to 60 years. They are closely followed by Hungarian men. On the other side of the figure, Austrian females can achieve the lowest accrual, which is reasonable in view of their starting point of the longest life expectancy.

HungaRian Statistical ReVIEW, Volume 4, NumBER 1, PP. 17-50. DOI: 10.35618/hsr2021.01.en017 
Figure 5. Country comparison: gains in life expectancies between the best and worst health statuses split by gender

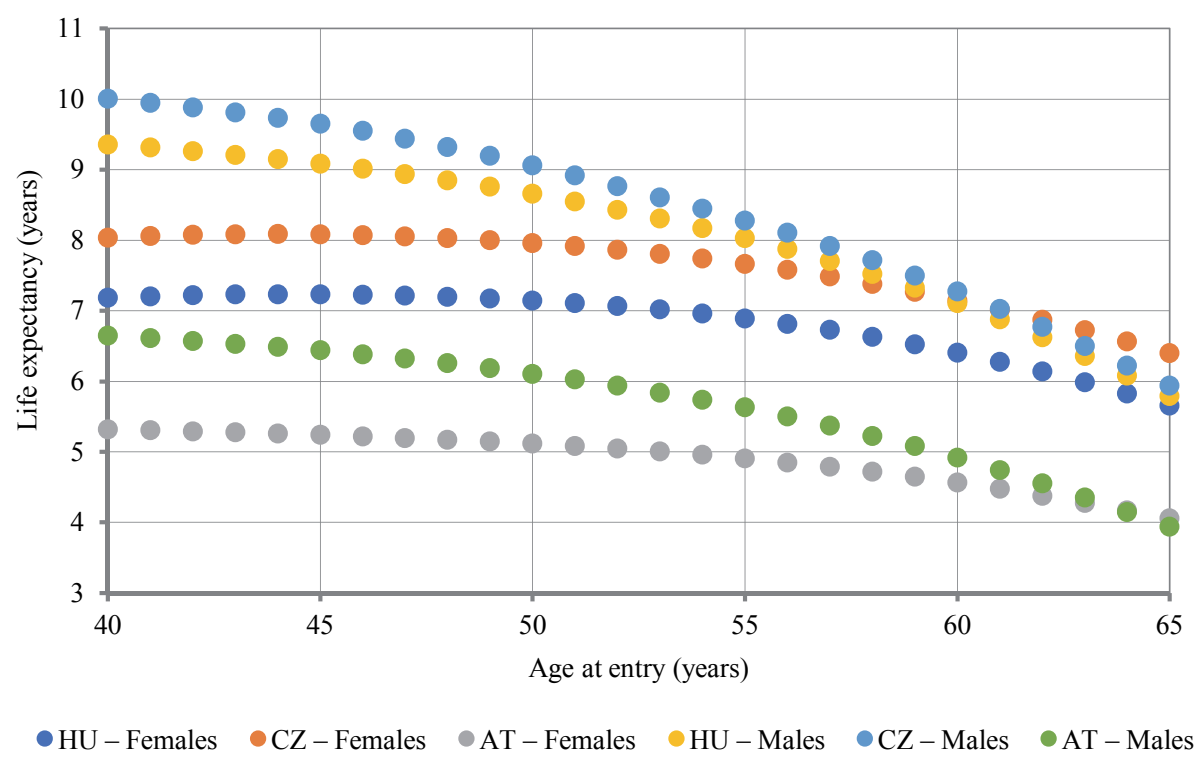

\section{Conclusion}

This study revealed that prevention of the major death causes can be supported by an effective risk assessment tool. As the first step, ANN provided an appropriate model for generating mortality rates due to cardiovascular diseases for each individual based on gender, age, smoker status, systolic blood pressure, and total cholesterol. Subsequently, adjustment of these probabilities enabled reproducing actual death cases by involving country-specific circumstances and more prudent and plausible life expectancies could be determined. The differences in life expectancy between an initial and an envisaged health status are easy to communicate and understand, hence, they can be widely applied. Furthermore, the use of such tools is not coupled with resource-intensive requirements, which can accelerate their spread.

Nevertheless, the applied method has some limitations. Risks arising from cardiovascular diseases may depend on supplementary risk factors in addition to the five involved dimensions. Furthermore, as the dataset was restricted to $40-65$ years, ages below and above the range could not be validated. The adjustment of probabilities was carried out only at the level of age groups. The combination-specific survival

Hungarian Statistical ReVIEW, Volume 4, NuMBER 1, PP. 17-50. DOI: 10.35618/hsr2021.01.en017 
rates may differ from the applied general ones; however, the results (i.e. the potential gains as differences) are prudent as life expectancies pertaining to better health statuses are underestimated, while those of worse life expectancies are overestimated. In addition to life expectancies, health statuses can be translated into healthy life expectancies, which can provide more insights into the risks inherent in lifestyles. Finally, given the lack of more detailed public life expectancy calculations, a comparison between the combination-specific results of the present study and figures provided by statistical offices could not be achieved.

Future research may extend the risk assessment tool by investigating other risk types so that involving them can enhance the effectiveness of prevention. Table 22 reveals mortality data by causes of deaths in Hungary, which can enable identification of the areas where interventions are needed.

Table 22

Mortality by group of causes of death in Hungary, 2019

\begin{tabular}{l|r|r}
\hline \multicolumn{1}{c|}{ Group of causes of death } & Number of deaths & Share (\%) \\
\hline Infectious and parasitic diseases & 686 & 0.53 \\
\hline Neoplasms & 32,638 & 25.18 \\
\hline Diseases of the circulatory system & 63,609 & 49.08 \\
\hline Diseases of the respiratory system & 8,315 & 6.42 \\
\hline Diseases of the digestive system & 6,354 & 4.90 \\
\hline Accidents & 3,576 & 2.76 \\
\hline Suicides & 1,550 & 1.20 \\
\hline Other & 12,875 & 9.93 \\
\hline Population, 1 January 2019 & 129,603 & 100.00 \\
\hline
\end{tabular}

Source: HCSO e-Shelf([2021] Tables 1.1 and 2.1).

The country comparison outlined in Table 23 points to a presumed phenomenon that within the country group at high risk, improving effective primary prevention and public health care (e.g. shifting from the Hungarian values to the Czech ones) may result in more harvestable gains for individuals striving towards the best health status. On obtaining the low cardiovascular rates and passing into the eminent country group (here the comparison between the Czech Republic representing an interim phase and Austria), the general system-level improvement provides more realisable increments for individuals being in less favourable health statuses. Further research may find evidence for this phenomenon.

HungaRian Statistical ReVIEW, Volume 4, NumBER 1, PP. 17-50. DOI: 10.35618/hsr2021.01.en017 


\begin{tabular}{|c|c|c|c|c|c|c|c|c|c|}
\hline \multirow{3}{*}{ Country } & \multirow{3}{*}{ Age } & \multicolumn{4}{|c|}{ Life expectancy } & \multicolumn{4}{|c|}{ Difference in life expectancy } \\
\hline & & \multicolumn{2}{|c|}{ Females } & \multicolumn{2}{|c|}{ Males } & \multicolumn{2}{|c|}{ Females } & \multicolumn{2}{|c|}{ Males } \\
\hline & & Best & Worst & Best & Worst & Best & Worst & Best & Worst \\
\hline \multirow[t]{2}{*}{ Hungary } & 40 & 43.4 & 36.2 & 37.4 & 28.0 & & & & \\
\hline & 65 & 21.2 & 15.6 & 17.1 & 11.3 & & & & \\
\hline \multirow[t]{2}{*}{ Czech Republic } & 40 & 45.8 & 37.8 & 39.7 & 29.7 & 2.4 & 1.6 & 2.3 & 1.7 \\
\hline & 65 & 23.0 & 16.6 & 18.2 & 12.3 & 1.8 & 1.0 & 1.2 & 1.0 \\
\hline \multirow[t]{2}{*}{ Austria } & 40 & 46.6 & 41.3 & 42.3 & 35.7 & 0.8 & 3.5 & 2.6 & 6.0 \\
\hline & 65 & 23.4 & 19.3 & 20.0 & 16.1 & 0.4 & 2.7 & 1.8 & 3.8 \\
\hline
\end{tabular}

Cardiovascular risks can be mitigated by utilising simple measures. Quantifying risks in the form of life expectancy can ensure the stimulus for reducing risk factors represented by poor-quality diet, smoking, alcohol, or low physical activity. Integrating risk assessment tools into existing practices of corporate well-being programmes can promote prevention with immediate effects for nearly zero costs, while potentials can be unleashed to the benefit of stakeholders not only at individual but also company and country level. The maximum realisable gain through prevention of cardiovascular diseases can result in additional $(43.4-36.2=) 7.2$ years for 40-year-old females and $(37.4-28.0=) 9.4$ years for males in Hungary while the respective figures are $(45.8-37.8=) \quad 8.0$ years and $(39.7-29.7=) 10.0$ years in the Czech Republic, $(46.6-41.3=) 5.3$ years and $(42.3-35.7=) 6.6$ years in Austria. Elderly people of 65 years may benefit from $(21.2-15.6=) 5.7^{5}$ years (women) or $(17.1-11.3=) 5.8$ years (men) in Hungary, $(23.0-16.6=) 6.4$ years (women) or $(18.2-12.3=) 5.9$ years $(m e n)$ in the Czech Republic, and from $(23.4-19.3=)$ 4.1 years (women) or $(20.0-16.1=) 3.9$ years $($ men $)$ in Austria.

\section{References}

ALDANA, S. [2001]: Financial impact of health promotion programs: A comprehensive review of the literature. American Journal of Health Promotion Vol. 15. No. 5. pp. 296-320. https://doi.org/10.4278/0890-1171-15.5.296

BAicker, K. - Cutler, D. - SONG, Z. [2010]: Workplace wellness programs can generate savings. Health Affairs. Vol. 29. No. 2. pp. 304-311. https://doi.org/10.1377/hlthaff.2009.0626

${ }^{5}$ The indicated figures are correct, the difference in the decimal place is due to rounding. 
BARNA, B. - FoDOR, S. [2018]: Gamifikált közösségi megoldás használata a kedvezőbb munkahelyi légkör kialakítása érdekében. Budapest Management Review/Vezetéstudomány. Vol. XLIX. No. 3. pp. 2-10. https://doi.org/10.14267/VEZTUD.2018.03.01

Baxter, S. - Sanderson, K. - Venn, A. - Blizzard, C. - Palmer, A. [2014]: The relationship between return on investment and quality of study methodology in workplace health promotion programs. American Journal of Health Promotion. Vol. 28. No. 6. pp. 347-363. https://doi.org/10.4278/ajhp.130731-LIT-395

DANNA, K. - GRIFFIN, R. [1999]: Health and well-being in the workplace: A review and synthesis of the literature. Journal of Management. Vol. 25. No. 3. pp. 357-384. https://doi.org/10.1177/014920639902500305

EuROPEAN SOCIETY OF CARDIOLOGY [2016]: 2016 European Guidelines on cardiovascular disease prevention in clinical practice. European Journal of Preventive Cardiology. Vol. 23. No. 11. pp. NP1-NP96. https://doi.org/10.1177/2047487316653709

Goetzel, R. - ANDERson, D. - WhitMer, W. - OzMinKowski, R. - DunN, R. - WASSERman, J. [1998]: The relationship between modifiable health risks and health care expenditures An analysis of the multi-employer HERO health risk and cost database. Journal of Occupational \& Environmental Medicine. Vol. 40. No. 10. pp. 843-854. https://doi.org/10.1097/00043764-199810000-00003

Goetzel, R. - Pei, X. - Tabrizi, M. - Henke, R. - Kowlessar, N. - Nelson, C. - MetZ, R. [2012]: Ten modifiable health risk factors are linked to more than one-fifth of employer-employee health care spending. Health Affairs. Vol. 31. No. 11. pp. 2474-2484. https://doi.org/10.1377/hlthaff.2011.0819

Grimani, A. - Aboagye, E. - KWAK, L. [2019]: The effectiveness of workplace nutrition and physical activity interventions in improving productivity, work performance and workability: A systematic review. BMC Public Health. Vol. 19. Article No. 1676. pp. 1-12. https://doi.org/10.1186/s12889-019-8033-1

KovÁcs, E. - Martos, T. [2018]: Patterns of optimism and employee well-being. Budapest Management Review/Vezetéstudomány. Vol. XLIX. No. 11. pp. 35-44. https://doi.org/ 10.14267/VEZTUD.2018.11.04

Krekel, C. - Ward, G. - De Neve, J.-E. [2019]: Employee Wellbeing, Productivity and Firm Performance. CEP Discussion Paper. No. 1605. https://doi.org/10.2139/ssrn.3356581

hCSO (Hungarian Central Statistical Office) [2020a]: Demographic Yearbook, 2019. Budapest.

Loef, M. - Walach, H. [2012]: The combined effects of healthy lifestyle behaviors on all cause mortality: A systematic review and meta-analysis. Preventive Medicine. Vol. 55. No. 3. pp. 163-170. https://doi.org/10.1016/j.ypmed.2012.06.017

OECD (ORGANISATION FOR ECONOMIC CO-OPERATION AND DEVELOPMENT) - EOHSP (EUROPEAN Observatory on Health Systems and Policies) [2019a]: Czechia: Country Health Profile 2019, State of Health in the EU. OECD Publishing-EOHSP. Paris, Brussels. https://www.oecd-ilibrary.org/deliver/058290e9-en.pdf?itemId $=\% 2$ Fcontent $\% 2$ Fpublication $\% 2$ F058290e9-en\&mimeType $=$ pdf

Hungarian Statistical ReVIEW, VOlume 4, NumBER 1, PP. 17-50. DOI: 10.35618/hsr2021.01.en017 
OECD - EOHSP [2019b]: Hungary: Country Health Profile 2019, State of Health in the EU. OECD Publishing-EOHSP. Paris, Brussels. https://www.oecd-ilibrary.org/deliver/ 4b7ba48c-en.pdf?itemId=\%2Fcontent $\% 2$ Fpublication $\% 2$ F4b 7 ba $48 \mathrm{c}$-en\&mimeType $=$ pdf

OECD - EOHSP [2019c]: Spain: Country Health Profile 2019, State of Health in the EU. OECD Publishing-EOHSP. Paris, Brussels. https://www.oecd-ilibrary.org/deliver/8f834636-en.pdf? itemId $=\% 2$ Fcontent $\% 2$ Fpublication $\% 2$ F8f834636-en\&mimeType $=$ pdf

PÉTER, E. - Keller, K. - KASZÁs, N. [2013]: Egészségtudatosság - része a szervezeti kultúrának? Budapest Management Review/Vezetéstudomány. Vol. ILIV. Special Issue No. 6. pp. 52-58.

Pinheiro, L. - Reshetnyak, E. - Sterling, M. - Richman, J. - Kern, L. -SAfFord, M. [2019]: Using health-related quality of life to predict cardiovascular disease events. Quality of Life Research. Vol. 28. No. 6. pp. 1465-1475. https://doi.org/10.1007/s11136-019-02103-1

SzABÓ, Á. - JUHÁsz, P. [2019]: A munkahelyi egészségprogramok mint kockázatkezelési eszközök. Gazdaság és Pénzügy. Vol. VI. No. 2. pp. 154-177. https://doi.org/10.33926/GP.2019.2.2

UNDP (United Nations Development Programme) [2018]: Human Development Indices and Indicators - 2018 Statistical Update. New York. http://hdr.undp.org/sites/default/ files/2018_human_development_statistical_update.pdf

UNDP [2020]: Human Development Report 2020. New York. http://hdr.undp.org/ sites/default/files/hdr2020.pdf

United NATIONS [2020]: A/RES/70/1 Resolution adopted by the General Assembly on 25 September 2015 - Transforming Our World: The 2030 Agenda for Sustainable Development. https://www.un.org/en/development/desa/population/migration/generalassembly/ docs/globalcompact/A_RES_70_1_E.pdf

VONA, G. [2020]: Boosting gains in healthy life expectancy through excelling in achieving SDGs. Köz-Gazdaság. Vol. 15. No. 2. pp. 96-107. https://doi.org/10.14267/RETP2020.02.14

\section{Internet references}

Czech Statistical Office [2021a]: Deaths: by detailed list of causes of death, sex and age. In: Demographic Yearbook of the Czech Republic - 2019. https://www.czso.cz/documents/ 10180/121768536/13006720rg05.xlsx/6cfdb23d-bdfe-4238-91bb-2c3c8d1a30d2?version=1.1

Czech Statistical Office [2021b]: Life table. https://www.czso.cz/documents/10180/97674865/ cr_ut_1920_2019.zip/79225f74-8abf-44b0-8ded-194d38194e0c?version=1.1

Czech Statistical Office [2021c]: Population by sex and age as of $31^{\text {st }}$ December of 2018 in the Czech Republic. Public database. https://vdb.czso.cz/vdbvo2/faces/en/index.jsf?page $=$ vystup-objekt\& $\mathrm{z}=\mathrm{T} \& \mathrm{f}=\mathrm{TABULKA} \& \mathrm{katalog}=33156 \& \mathrm{pvo}=\mathrm{DEMD001} \& \mathrm{str}=\mathrm{v} 4 \& \mathrm{c}=$ v3 2_RP2018MP12DP31

EC (EuROPEAN COMMISSION) [2021]: Mortality and life expectancy statistics. https://ec.europa.eu/ eurostat/statistics-explained/index.php?title=Mortality_and_life_expectancy_statistics

IBM (INTERNATIONAL BUSINESS MACHINES CORPORATION) [2016]: IBM SPSS Statistics 24 Algorithms. $\mathrm{ftp}: / / \mathrm{ftp}$. software.ibm.com/software/analytics/spss/documentation/statistics/24.0/en/client/M anuals/IBM_SPSS_Statistics_Algorithms.pdf 
HCSO [2020b]: Population by sex and age as of $1^{\text {st }}$ January of 2019 in Hungary. In: Statistical Yearbook of Hungary, 2018. https://www.ksh.hu/shelf

HCSO E-SHELF [2021]: Statistical Yearbook of Hungary, 2019. https://www.ksh.hu/shelf

HCSO [2021a]: Population and vital events - 22.1.1.9. Number of deaths and rate, infant mortality per thousand live-born, average life expectancy at birth, deaths by main reasons of death. http://www.ksh.hu/stadat_files/nep/en/nep0009.html

HCSO [2021b]: Business units and non-profit organisations - 9.1.1.1. Summary data (2000-2020). http://www.ksh.hu/stadat_files/gsz/en/gsz0001.html

OECD ILIBRARY [2021]: Smoking Among Adults. https://www.oecd-ilibrary.org/sites/21ac51dden/index.html?itemId=/content/component/21ac51dd-en

Office for National Statistics. [2021]: National Life Tables, United Kingdom, 1980-1982 to 2017-2019. https://www.ons.gov.uk/file?uri=/peoplepopulationandcommunity/birthsdeath sandmarriages/lifeexpectancies/datasets/nationallifetablesunitedkingdomreferencetables/curr ent/nationallifetables3yearuk.xlsx

STATISTIK AuSTRIA [2021a]: Sterbetafeln. https://www.statistik.at/wcm/idc/idcplg?IdcService= GET_NATIVE_FILE\&RevisionSelectionMethod $=$ LatestReleased\&dDocName $=022707$

STATISTIK AUSTRIA [2021b]: Todesursachen. https://www.statistik.at/wcm/idc/idcplg?IdcService= GET_NATIVE_FILE\&RevisionSelectionMethod=LatestReleased\&dDocName $=021987$

StATISTIK Austria [2021c]: Population 2018 by Age, Sex and Laender. https://www.statistik.at/wcm/idc/idcplg?IdcService=GET_NATIVE_FILE\&RevisionSelecti onMethod=LatestReleased\&dDocName $=118745$

WHO (World Health ORganisation) [2019]: International Statistical Classification of Diseases and Related Health Problems, $10^{\text {th }}$ Revision. https://icd.who.int/browse10/2019/en

WHO [2021]: About Cardiovascular Diseases. https://www.who.int/cardiovascular_diseases/ about_cvd/en/ 